Chapter 21

\title{
THE FINANCIAL ACCELERATOR IN A QUANTITATIVE BUSINESS CYCLE FRAMEWORK*
}

\author{
BEN S. BERNANKE, MARK GERTLER and SIMON GILCHRIST \\ Princeton University, New York University, and Boston University**
}

\section{Contents}

$\begin{array}{lr}\text { Abstract } & 1342\end{array}$

$\begin{array}{lr}\text { Keywords } & 1342\end{array}$

1. Introduction 1343

2. The model: overview and basic assumptions 1346

3. The demand for capital and the role of net worth 1349

3.1. Contract terms when there is no aggregate risk 1350

3.2. Contract terms when there is aggregate risk 1352

3.3. Net worth and the optimal choice of capital 1352

4. General equilibrium 1355

4.1. The entrepreneurial sector 1356

$\begin{array}{ll}\text { 4.2. The complete log-linearized model } & 1360\end{array}$

$\begin{array}{ll}\text { 4.2.1. Two extensions of the baseline model } & 1365\end{array}$

4.2.1.1. Investment delays $\quad 1365$

4.2.1.2. Heterogeneous firms $\quad 1366$

5. Model simulations $\quad 1367$

$\begin{array}{ll}\text { 5.1. Model parametrization } & 1367\end{array}$

$\begin{array}{ll}\text { 5.2. Results } & 1368 \\ & 1368\end{array}$

5.2.1. Response to a monetary policy shock 1368

$\begin{array}{ll}\text { 5.2.2. Shock to technology, demand, and wealth } & 1372\end{array}$

$\begin{array}{ll}\text { 5.2.3. Investment delays and heterogeneous firms } & 1373\end{array}$

6. A highly selected review of the literature $\quad 1375$

$\begin{array}{ll}\text { 7. Directions for future work } & 1379\end{array}$

Appendix A. The optimal financial contract and the demand for capital 1380

$\begin{array}{ll}\text { A.1. The partial equilibrium contracting problem } & 1380\end{array}$

$\begin{array}{lr}\text { A.2. The log-normal distribution } & 1385\end{array}$

$\begin{array}{ll}\text { A.3. Aggregate risk } & 1385\end{array}$

* Thanks to Michael Woodford, Don Morgan and John Taylor for helpful comments, and to the NSF and C.V. Starr Center for financial support.

*** Each author is also affiliated with the National Bureau of Economic Research.

Handbook of Macroeconomics, Volume 1, Edited by J.B. Taylor and M. Woodford

(C) 1999 Elsevier Science B.V. All rights reserved 
Appendix B. Household, retail and government sectors

B.1. Households

B.2. The retail sector and price setting

B.3. Government sector

1389

References

1390

\begin{abstract}
This chapter develops a dynamic general equilibrium model that is intended to help clarify the role of credit market frictions in business fluctuations, from both a qualitative and a quantitative standpoint. The model is a synthesis of the leading approaches in the literature. In particular, the framework exhibits a "financial accelerator", in that endogenous developments in credit markets work to amplify and propagate shocks to the macroeconomy. In addition, we add several features to the model that are designed to enhance the empirical relevance. First, we incorporate money and price stickiness, which allows us to study how credit market frictions may influence the transmission of monetary policy. In addition, we allow for lags in investment which enables the model to generate both hump-shaped output dynamics and a lead-lag relation between asset prices and investment, as is consistent with the data. Finally, we allow for heterogeneity among firms to capture the fact that borrowers have differential access to capital markets. Under reasonable parametrizations of the model, the financial accelerator has a significant influence on business cycle dynamics.
\end{abstract}

\title{
Keywords
}

financial accelerator, business fluctuations, monetary policy

JEL classification: $\mathrm{E} 30, \mathrm{E} 44, \mathrm{E} 50$ 


\section{Introduction}

The canonical real business cycle model and the textbook Keynesian IS-LM model differ in many fundamental ways. However, these two standard frameworks for macroeconomic analysis do share one strong implication: Except for the term structure of real interest rates, which, together with expectations of future payouts, determines real asset prices, in these models conditions in financial and credit markets do not affect the real economy. In other words, these two mainstream approaches both adopt the assumptions underlying the Modigliani-Miller (1958) theorem, which implies that financial structure is both indeterminate and irrelevant to real economic outcomes.

Of course, it can be argued that the standard assumption of financial-structure irrelevance is only a simplification, not to be taken literally, and not harmful if the "frictions" in financial and credit markets are sufficiently small. However, as Gertler (1988) discusses, there is a long-standing alternative tradition in macroeconomics, beginning with Fisher and Keynes if not earlier authors, that gives a more central role to credit-market conditions in the propagation of cyclical fluctuations. In this alternative view, deteriorating credit-market conditions - sharp increases in insolvencies and bankruptcies, rising real debt burdens, collapsing asset prices, and bank failures are not simply passive reflections of a declining real economy, but are in themselves a major factor depressing economic activity. For example, Fisher (1933) attributed the severity of the Great Depression in part to the heavy burden of debt and ensuing financial distress associated with the deflation of the early $1930 \mathrm{~s}$, a theme taken up half a century later by Bernanke (1983). More recently, distressed banking systems and adverse credit-market conditions have been cited as sources of serious macroeconomic contractions in Scandinavia, Latin America, Japan, and other East Asian countries. In the US context, both policy-makers and academics have put some of the blame for the slow recovery of the economy from the 1990-1991 recession on heavy corporate debt burdens and an undercapitalized banking system [see, e.g., Bernanke and Lown (1992)]. The feedbacks from credit markets to the real economy in these episodes may or may not be as strong as some have maintained; but it must be emphasized that the conventional macroeconomic paradigms, as usually presented, do not even give us ways of thinking about such effects.

The principal objective of this chapter is to show that credit-market imperfections can be incorporated into standard macroeconomic models in a relatively straightforward yet rigorous way. Besides our desire to be able to evaluate the role of creditmarket factors in the most dramatic episodes, such as the Depression or the more recent crises (such as those in East Asia), there are two additional reasons for attempting to bring such effects into mainstream models of economic fluctuations. First, it appears that introducing credit-market frictions into the standard models can help improve their ability to explain even "garden-variety" cyclical fluctuations. In particular, in the context of standard dynamic macroeconomic models, we show in this chapter that credit-market frictions may significantly amplify both real and nominal shocks to the economy. This extra amplification is a step toward resolving the puzzle of how 
relatively small shocks (modest changes in real interest rates induced by monetary policy, for example, or the small average changes in firm costs induced by even a relatively large movement in oil prices) can nevertheless have large real effects. Introducing credit-market frictions has the added advantage of permitting the standard models to explain a broader class of important cyclical phenomena, such as changes in credit extension and the spreads between safe and risky interest rates.

The second reason for incorporating credit-market effects into mainstream models is that modern empirical research on the determinants of aggregate demand and (to a lesser extent) of aggregate supply has often ascribed an important role to various credit-market frictions. Recent empirical work on consumption, for example, has emphasized the importance of limits on borrowing and the closely-related "buffer stock" behavior [Mariger (1987), Zeldes (1989), Jappelli (1990), Deaton (1991), Eberly (1994), Gourinchas and Parker (1995), Engelhardt (1996), Carroll (1997), Ludvigson (1997), Bacchetta and Gerlach (1997)]. In the investment literature, despite some recent rehabilitation of a role for neoclassical cost-of-capital effects [Cummins, Hassett and Hubbard (1994), Hassett and Hubbard (1996)], there remains considerable evidence for the view that cash flow, leverage, and other balance-sheet factors also have a major influence on investment spending [Fazzari, Hubbard and Petersen (1988), Hoshi, Kashyap and Scharfstein (1991), Whited (1992), Gross (1994), Gilchrist and Himmelberg (1995), Hubbard, Kashyap and Whited (1995) $]^{1}$. Similar conclusions are reached by recent studies of the determinants of inventories and of employment [Cantor (1990), Blinder and Maccini (1991), Kashyap, Lamont and Stein (1994), Sharpe (1994), Carpenter, Fazzari and Petersen (1994)]. Aggregate modeling, if it is to describe the dynamics of spending and production realistically, needs to take these empirical findings into account ${ }^{2}$.

How does one go about incorporating financial distress and similar concepts into macroeconomics? While it seems that there has always been an empirical case for including credit-market factors in the mainstream model, early writers found it difficult to bring such apparently diverse and chaotic phenomena into their formal analyses. As a result, advocacy of a role for these factors in aggregate dynamics fell for the most part to economists outside the US academic mainstream, such as Hyman Minsky, and to some forecasters and financial-market practitioners, such as Otto Eckstein and Allen Sinai (1986), Albert Wojnilower (1980), and Henry Kaufman (1986). However, over the past twenty-five years, breakthroughs in the economics of incomplete and asymmetric information [beginning with Akerlof (1970)] and the extensive adoption of these ideas in corporate finance and other applied fields [e.g., Jensen and Meckling (1976)], have made possible more formal theoretical

\footnotetext{
1 A critique of the cash-flow literature is given by Kaplan and Zitngales (1997). See Chirinko (1993) for a broad survey of the empirical literature in investment.

2 Contemporary macroeconometric forecasting models, such as the MPS model used by the Federal Reserve, typically do incorporate factors such as borrowing constraints and cash-flow effects. See for example Brayton et al. (1997).
} 
analyses of credit-market imperfections. In particular, it is now well understood that asymmetries of information play a key role in borrower-lender relationships; that lending institutions and financial contracts typically take the forms that they do in order to reduce the costs of gathering information and to mitigate principal-agent problems in credit markets; and that the common feature of most of the diverse problems that can occur in credit markets is a worsening of informational asymmetries and increases in the associated agency costs. Because credit-market crises (and less dramatic malfunctions) increase the real costs of extending credit and reduce the efficiency of the process of matching lenders and potential borrowers, these events may have widespread real effects. In short, when credit markets are characterized by asymmetric information and agency problems, the Modigliani-Miller irrelevance theorem no longer applies.

Drawing on insights from the literature on asymmetric information and agency costs in lending relationships, in this chapter we develop a dynamic general equilibrium model that we hope will be useful for understanding the role of credit-market frictions in cyclical fluctuations. The model is a synthesis of several approaches already in the literature, and is partly intended as an expository device. But because it combines attractive features of several previous models, we think the framework presented here has something new to offer. Importantly, we believe that the model is of some use in assessing the quantitative implications of credit-market frictions for macroeconomic analysis.

In particular, our framework exhibits a "financial accelerator" [Bernanke, Gertler and Gilchrist (1996)], in that endogenous developments in credit markets work to propagate and amplify shocks to the macroeconomy. The key mechanism involves the link between "external finance premium" (the difference between the cost of funds raised externally and the opportunity cost of funds internal to the firm) and the net worth of potential borrowers (defined as the borrowers' liquid assets plus collateral value of illiquid assets less outstanding obligations). With credit-market frictions present, and with the total amount of financing required held constant, standard models of lending with asymmetric information imply that the external finance premium depends inversely on borrowers' net worth. This inverse relationship arises because, when borrowers have little wealth to contribute to project financing, the potential divergence of interests between the borrower and the suppliers of external funds is greater, implying increased agency costs; in equilibrium, lenders must be compensated for higher agency costs by a larger premium. To the extent that borrowers' net worth is procyclical (because of the procyclicality of profits and asset prices, for example), the external finance premium will be countercyclical, enhancing the swings in borrowing and thus in investment, spending, and production.

We also add to the framework several features designed to enhance the empirical relevance. First, we incorporate price stickiness and money into the analysis, using modeling devices familiar from New Keynesian research, which allows us to study the effects of monetary policy in an economy with credit-market frictions. In addition, we allow for decision lags in investment, which enables the model to generate both 
hump-shaped output dynamics and a lead-lag relationship between asset prices and investment, as is consistent with the data. Finally, we allow for heterogeneity among firms to capture the real-world fact that borrowers have differential access to capital markets. All these improvements significantly enhance the value of the model for quantitative analysis, in our view.

The rest of the chapter is organized as follows. Section 2 introduces the model analyzed in the present chapter. Section 3 considers the source of the financial accelerator: a credit-market friction which evolves from a particular form of asymmetric information between lenders and potential borrowers. It then performs a partial equilibrium analysis of the resulting terms of borrowing and of firms' demand for capital, and derives the link between net worth and the demand for capital that is the essence of the financial accelerator. Section 4 embeds the credit-market model in a Dynamic New Keynesian (DNK) model of the business cycle, using the device proposed by Calvo (1983) to incorporate price stickiness and a role for monetary policy; it also considers several extensions, such as allowing for lags in investment and for differential credit access across firms. Section 5 presents simulation results, drawing comparisons between the cases including and excluding the credit-market friction. Here we show that the financial accelerator works to amplify and propagate shocks to the economy in a quantitatively significant way. Section 6 then gives a brief and selective survey that describes how the framework present fits in the literature. Section 7 then describes several directions for future research. Two appendices contain additional discussion and analysis of the partial-equilibrium contracting problem and the dynamic general equilibrium model in which the contracting problem is embedded.

\section{The model: overview and basic assumptions}

Our model is a variant of the Dynamic New Keynesian (DNK) framework, modified to allow for financial accelerator effects on investment. The baseline DNK model is essentially a stochastic growth model that incorporates money, monopolistic competition, and nominal price rigidities. We take this framework as the starting point for several reasons. First, this approach has become widely accepted in the literature ${ }^{3}$. It has the qualitative empirical appeal of the IS-LM model, but is motivated from first principles. Second, it is possible to study monetary policy with this framework. For our purposes, this means that it is possible to illustrate how credit market imperfections influence the transmission of monetary policy, a theme emphasized in much of the recent literature ${ }^{4}$. Finally, in the limiting case of perfect price flexibility, the cyclical properties of the model closely resemble those of a real business cycle framework. In

\footnotetext{
3 See Goodfriend and King (1997) for an exposition of the DNK approach.

4 For a review of the recent literature on the role of credit market frictions in the transmission of monetary policy, see Bernanke and Gertler (1995).
} 
this approximate sense, the DNK model nests the real business cycle paradigm as a special case. It thus has the virtue of versatility.

Extending any type of contemporary business cycle model to incorporate financial accelerator effects is, however, not straightforward. There are two general problems: First, because we want lending and borrowing to occur among private agents in equilibrium, we cannot use the representative agent paradigm but must instead grapple with the complications introduced by heterogeneity among agents. Second, we would like the financial contracts that agents use in the model to be motivated as far as possible from first principles. Since financial contracts and institutions are endogenous, results that hinge on arbitrary restrictions on financial relationships may be suspect. Most of the nonstandard assumptions that we make in setting up our model are designed to facilitate aggregation (despite individual heterogeneity) and permit an endogenous financial structure, thus addressing these two key issues.

The basic structure of our model is as follows: There are three types of agents, called households, entrepreneurs, and retailers. Households and entrepreneurs are distinct from one another in order to explicitly motivate lending and borrowing. Adding retailers permits us to incorporate inertia in price setting in a tractable way, as we discuss. In addition, our model includes a government, which conducts both fiscal and monetary policy.

Households live forever; they work, consume, and save. They hold both real money balances and interest-bearing assets. We provide more details on household behavior below.

For inducing the effect we refer to as the financial accelerator, entrepreneurs play the key role in our model. These individuals are assumed to be risk-neutral and have finite horizons: Specifically, we assume that each entrepreneur has a constant probability $\gamma$ of surviving to the next period (implying an expected lifetime of $\frac{1}{1-\gamma}$ ). The assumption of finite horizons for entrepreneurs is intended to capture the phenomenon of ongoing births and deaths of firms, as well as to preclude the possibility that the entrepreneurial sector will ultimately accumulate enough wealth to be fully self-financing. Having the survival probability be constant (independent of age) facilitates aggregation. We assume the birth rate of entrepreneurs to be such that the fraction of agents who are entrepreneurs is constant.

In each period $t$ entrepreneurs acquire physical capital. (Entrepreneurs who "die" in period $t$ are not allowed to purchase capital, but instead simply consume their accumulated resources and depart from the scene.) Physical capital acquired in period $t$ is used in combination with hired labor to produce output in period $t+1$, by means of a constant-returns to scale technology. Acquisitions of capital are financed by entrepreneurial wealth, or "net worth", and borrowing.

The net worth of entrepreneurs comes from two sources: profits (including capital gains) accumulated from previous capital investment and income from supplying labor (we assume that entrepreneurs supply one unit of labor inelastically to the general labor market). As stressed in the literature, entrepreneurs' net worth plays a critical role in the dynamics of the model. Net worth matters because a borrower's financial position 
is a key determinant of his cost of external finance. Higher levels of net worth allow for increased self-financing (equivalently, collateralized external finance), mitigating the agency problems associated with external finance and reducing the external finance premium faced by the entrepreneur in equilibrium.

To endogenously motivate the existence of an external finance premium, we postulate a simple agency problem that introduces a conflict of interest between a borrower and his respective lenders. The financial contract is then designed to minimize the expected agency costs. For tractability we assume that there is enough anonymity in financial markets that only one-period contracts between borrowers and lenders are feasible [a similar assumption is made by Carlstrom and Fuerst (1997)]. Allowing for longer-term contracts would not affect our basic results ${ }^{5}$. The form of the agency problem we introduce, together with the assumption of constant returns to scale in production, is sufficient (as we shall see) to generate a linear relationship between the demand for capital goods and entrepreneurial net worth, which facilitates aggregation.

One complication is that to introduce the nominal stickiness intrinsic to the DNK framework, at least some suppliers must be price setters, i.e., they must face downward-sloping demand curves. However, assuming that entrepreneurs are imperfect competitors complicates aggregation, since in that case the demand for capital by individual firms is no longer linear in net worth. We avoid this problem by distinguishing between entrepreneurs and other agents, called retailers. Entrepreneurs produce wholesale goods in competitive markets, and then sell their output to retailers who are monopolistic competitors. Retailers do nothing other than buy goods from entrepreneurs, differentiate them (costlessly), then re-sell them to households. The monopoly power of retailers provides the source of nominal stickiness in the economy; otherwise, retailers play no role. We assume that profits from retail activity are rebated lump-sum to households. Having described the general setup of the model, we proceed in two steps. First, we derive the key microeconomic relationship of the model: the dependence of a firm's demand for capital on the potential borrower's net worth. To do so, we consider the firm's (entrepreneur's) partial equilibrium problem of jointly determining its demand for capital and terms of external finance in negotiation with a competitive lender (e.g., a financial intermediary). Second, we embed these relationships in an otherwise conventional DNK model. Our objective is to show how fluctuations in borrowers' net worth can act to amplify and propagate exogenous shocks to the system. For most of the analysis we assume that there is a single type of firm; however, we eventually extend the model to allow for heterogeneous firms with differential access to credit.

\footnotetext{
5 So long as borrowers have finite horizons, net worth influences the terms of borrowing, even after allowing for multi-period contracts. See, for example, Gertler (1992).
} 


\section{The demand for capital and the role of net worth}

We now study the capital investment decision at the firm level, taking as given the price of capital goods and the expected return to capital. In the subsequent section we endogenize capital prices and returns as part of a general equilibrium solution.

At time $t$, the entrepreneur who manages firm $j$ purchases capital for use at $t+1$. The quantity of capital purchased is denoted $K_{t+1}^{j}$, with the subscript denoting the period in which the capital is actually used, and the superscript $j$ denoting the firm. The price paid per unit of capital in period $t$ is $Q_{t}$. Capital is homogeneous, and so it does not matter whether the capital the entrepreneur purchases is newly produced within the period or is "old", depreciated capital. Having the entrepreneur purchase (or repurchase) his entire capital stock each period is a modeling device to ensure, realistically, that leverage restrictions or other financial constraints apply to the firm as a whole, not just to the marginal investment.

The return to capital is sensitive to both aggregate and idiosyncratic risk. The ex post gross return on capital for firm $j$ is $\omega^{j} R_{t+1}^{k}$, where $\omega^{j}$ is an idiosyncratic disturbance to firm $j$ 's return and $R_{t+1}^{k}$ is the ex post aggregate return to capital (i.e., the gross return averaged across firms). The random variable $\omega^{j}$ is i.i.d. across time and across firms, with a continuous and once-differentiable c.d.f., $F(\omega)$, over a non-negative support, and $E\left\{\omega^{j}\right\}=1$. We impose the following restriction on the corresponding hazard rate $h(\omega)$ :

$$
\frac{\partial(\omega h(\omega))}{\partial \omega}>0
$$

where $h(\omega) \equiv \frac{\mathrm{d} F(\omega)}{1-F(\omega)}$. This regularity condition is a relatively weak restriction that is satisfied by most conventional distributions, including for example the log-normal.

At the end of period $t$ (going into period $t+1$ ) entrepreneur $j$ has available net worth, $N_{t+1}^{j}$. To finance the difference between his expenditures on capital goods and his net worth he must borrow an amount $B_{t+1}^{j}$, given by

$$
B_{t+1}^{j}=Q_{t} K_{i+1}^{j}-N_{i+1}^{j}
$$

The entrepreneur borrows from a financial intermediary that obtains its funds from households. The financial intermediary faces an opportunity cost of funds between $t$ and $t+1$ equal to the economy's riskless gross rate of return, $R_{t+1}$. The riskless rate is the relevant opportunity cost because in the equilibrium of our model, the intermediary holds a perfectly safe portfolio (it perfectly diversifies the idiosyncratic risk involved in lending). Because entrepreneurs are risk-neutral and households are risk-averse, the loan contract the intermediary signs has entrepreneurs absorb any aggregate risk, as we discuss below.

To motivate a nontrivial role for financial structure, we follow a number of previous papers in assuming a "costly state verification" (CSV) problem of the type first 
analyzed by Townsend (1979), in which lenders must pay a fixed "auditing cost" in order to observe an individual borrower's realized return (the borrower observes the return for free). As Townsend showed, this assumption allows us to motivate why uncollateralized external finance may be more expensive than internal finance without imposing arbitrary restrictions on the contract structure. There are many other specifications of the incentive problem between the entrepreneur and outside lenders that can generate qualitatively similar results. The virtues of the Townsend formulation are its simplicity and descriptive realism.

Following the CSV approach, we assume that the lender must pay a cost if he or she wishes to observe the borrower's realized return on capital. This auditing cost is interpretable as the cost of bankruptcy (including for example auditing, accounting, and legal costs, as well as losses associated with asset liquidation and interruption of business). The monitoring cost is assumed to equal a proportion $\mu$ of the realized gross payoff to the firm's capital, i.e., the monitoring cost equals $\mu \omega^{j} R_{t+1}^{k} Q_{t} K_{t+1}^{j}$. Although one might expect that there would be economies of scale in monitoring, the proportionality assumption is very convenient in our context and does not seem too unreasonable.

\subsection{Contract terms when there is no aggregate risk}

To describe the optimal contractual arrangement, it is useful to first work through the case where the aggregate return to capital $R_{t+1}^{k}$ is known in advance. In this instance the only uncertainty about the project's return is idiosyncratic to the firm, as in the conventional version of the CSV problem.

Absent any aggregate uncertainty, the optimal contract under costly state verification looks very much like standard risky debt (see Appendix A for a detailed analysis of the contracting problem): In particular, the entrepreneur chooses the value of firm capital, $Q_{t} K_{t+1}^{j}$, and the associated level of borrowing, $B_{t+1}^{j}$, prior to the realization of the idiosyncratic shock. Given $Q_{t} K_{t+1}^{j}, B_{t+1}^{j}$, and $R_{t+1}^{k}$, the optimal contract may be characterized by a gross non-default loan rate, $Z_{t+1}^{j}$, and a threshold value of the idiosyncratic shock $\omega^{j}$, call it $\bar{\omega}^{j}$, such that for values of the idiosyncratic shock greater than or equal to $\bar{\omega}^{j}$, the entrepreneur is able to repay the loan at the contractual rate, $Z_{t+1}^{j}$. That is, $\bar{\omega}^{j}$ is defined by

$$
\omega^{j} R_{t+1}^{k} Q_{t} K_{t+1}^{j}=Z_{t+1}^{j} B_{t+1}^{j}
$$

When $\omega^{j} \geqslant \bar{\omega}^{j}$, under the optimal contract the entrepreneur repays the lender the promised amount $Z_{i+1}^{j} B_{t+1}^{j}$ and keeps the difference, equal to $\omega^{j} R_{t+1}^{k} Q_{t} K_{t+1}^{j}-Z_{t+1}^{j} B_{t+1}^{j}$. If $\omega^{j}<\bar{\omega}^{j}$, the entrepreneur cannot pay the contractual return and thus declares default. In this situation the lending intermediary pays the auditing cost and gets to keep what it finds. That is, the intermediary's net receipts are $(1-\mu) \omega R_{i+1}^{k} Q_{t} K_{t+1}^{j}$. A defaulting entrepreneur receives nothing. 
The values of $\bar{\omega}^{j}$ and $Z_{t+1}^{j}$ under the optimal contract are determined by the requirement that the financial intermediary receive an expected return equal to the opportunity cost of its funds. Because the loan risk in this case is perfectly diversifiable, the relevant opportunity cost to the intermediary is the riskless rate, $R_{t+1}$. Accordingly, the loan contract must satisfy

$$
\left[1-F\left(\bar{\omega}^{j}\right)\right] Z_{t+1}^{j} B_{t+1}^{j}+(1-\mu) \int_{0}^{\bar{\omega}^{j}} \omega R_{t+1}^{k} Q_{t} K_{t+1}^{j} \mathrm{~d} F(\omega)=R_{t+1} B_{t+1}^{j},
$$

where the left-hand side of Equation (3.4) is the expected gross return on the loan to the entrepreneur and the right side is the intermediary's opportunity cost of lending. Note that $F\left(\bar{\omega}^{j}\right)$ gives the probability of default.

Combining Equations (3.2) and (3.3) with Equation (3.4) yields the following expression for $\bar{\omega}^{j}$ :

$$
\left[1-F\left(\bar{\omega}^{j}\right)\right] \bar{\omega}^{j}+(1-\mu) \int_{0}^{\bar{\omega}^{j}} \omega \mathrm{d} F(\omega) R_{t+1}^{k} Q_{t} K_{t+1}^{j}=R_{t+1}\left(Q_{t} K_{t+1}^{j}-N_{t+1}^{j}\right)
$$

By using Equation (3.4) to eliminate $Z_{t+1}^{j}$, we are able to express the lender's expected return simply as a function of the cutoff value of the firm's idiosyncratic productivity shock, $\bar{\omega}^{j}$. There are two effects of changing $\bar{\omega}^{j}$ on the expected return, and they work in opposite directions. A rise in $\bar{\omega}^{j}$ increases the non-default payoff; on the other hand, it also raises the default probability, which lowers the expected payoff. The assumed restrictions on the hazard function given by Equation (3.1) imply that the expected return reaches a maximum at an unique interior value of $\bar{\omega}^{j}:$ As $\bar{\omega}^{j}$ rises above this value the expected return declines due to the increased likelihood of default ${ }^{6}$. For values of $\bar{\omega}^{j}$ below the maximum, the function is increasing and concave $^{7}$. If the lender"s opportunity cost is so large that there does not exist a value of $\bar{\omega}^{j}$ that generates the required expected return, then the borrower is "rationed" from the market. Appendix A provides details. For simplicity, in what follows, we consider only equilibria without rationing, i.e., equilibria in which the equilibrium value of $\bar{\omega}^{j}$ always lies below the maximum feasible value ${ }^{8}$. Under the parametrizations we use later, this condition is in fact satisfied.

6 To see that the maximum must be in the interior of the support of $\omega$, note that as $\bar{\omega}^{\prime}$ approaches its upper bound, the default probability converges to unity. Appendix A shows that the interior optimum is unique.

7 The change in the expected payoff from a unit increase in $\bar{\omega}^{j}$ is $\left\{\left[1-F\left(\bar{\omega}^{j}\right)\right]-\mu \bar{\omega}^{\prime} \mathrm{d} F\left(\bar{\omega}^{j}\right)\right\} R_{t+1}^{k} Q_{t} K_{f+1}^{j}$ The first term in the expression in brackets reffects the rise in the non-default payoff. The second term reflects the rise in expected default costs. Note that we can rewrite this expression as $\left\{1-\mu \bar{\omega}^{j} h\left(\bar{\omega}^{j}\right)\right\}\left[1-F\left(\bar{\omega}^{j}\right)\right] R_{t+1}^{k} Q_{t} K_{t+1}^{j}$, where $h(\omega) \equiv \frac{\mathrm{d} F(\omega)}{1-F(\omega)}$ is the hazard rate. Given Equation (3.1), the derivative of this expression is negative for values of $\omega^{j}$ below the maximum one feasible, implying that the expected payoff is concave in this range.

8 Note also that since we are restricting attention to non-rationing equilibria, the lender's expected return is always increasing in $\bar{\omega}^{j}$. 


\subsection{Contract terms when there is aggregate risk}

With aggregate uncertainty present, $\bar{\omega}^{j}$ will in general depend on the ex post realization of $R_{i+1}^{k}$. Our assumption that the entrepreneur is risk-neutral leads to a simple contract structure, despite this complication. Because he cares only about the mean return on his wealth, the entrepreneur is willing to bear all the aggregate risk ${ }^{9}$. Thus he is willing to guarantee the lender a return that is free of any systematic risk, i.e., conditional on the ex post realization of $R_{t+1}^{k}$, the borrower offers a (state-contingent) non-default payment that guarantees the lender a return equal in expected value to the riskless rate. (Note that the only residual risk the lender bears arises from the idiosyncratic shock $\omega_{t+1}^{j}$, and is thus diversifiable.) Put differently, Equation (3.5) now implies a set of restrictions, one for each realization of $R_{t+1}^{k}$. The result is a schedule for $\bar{\omega}^{j}$, contingent on the realized aggregate state. As we are restricting attention to non-rationing equilibria, we consider only parametrizations where there in fact exists a value of $\bar{\omega}^{j}$ for each aggregate state that satisfies Equation (3.5). Diversification by intermediaries implies that households earn the riskless rate on their saving.

Descriptively, the existence of aggregate uncertainty effectively ties the risky loan rate $Z_{t+1}^{j}$ to macroeconomic conditions. In particular, the loan rate adjusts countercyclically. For example, a realization of $R_{t+1}^{k}$ that is lower than expected raises $Z_{t+1}^{j}$; that is, to compensate for the increased default probability due to the low average return to capital, the non-default payment must rise. This in turn implies an increase in the cutoff value of the idiosyncratic productivity shock, $\bar{\omega}^{j}$. Thus the model implies, reasonably, that default probabilities and default premia rise when the aggregate return to capital is lower than expected ${ }^{10}$.

\subsection{Net worth and the optimal choice of capital}

Thus far we have described how the state-contingent values of $\bar{\omega}^{j}$ and $Z_{t+1}^{j}$ are determined, given the ex post realization of $R_{t+1}^{k}$ and the ex ante choices of $Q_{t} K_{t+1}^{j}$ and $B_{t+1}^{j}$. We now turn to the entrepreneur's general problem of determining his demand for capital.

\footnotetext{
9 The entrepreneur's value function can be shown to be linear in wealth because (i) his utility is linear in consumption and (ii) the project he is investing in exhibits constant returns to scale. [See, e.g., Bernanke and Gertler $(1989,1990)$.]

10 This kind of state-contingent financial arrangement is a bit stylized, but may be thought of as corresponding to the following scenario: Let the maturity of the debt be shorter than the maturity of the firm's project. The debt is then rolled over after the realization of the aggregate uncertainty. If there is bad aggregate news, then the new loan rate is higher than would be otherwise. To implement the sort of risk-sharing arrangement implied by the model, therefore, all that is necessary is that some component of the financing have a shorter maturity than that of the project.
} 
Given the state-contingent debt form of the optimal contract, the expected return to the entrepreneur may be expressed as

$$
E\left\{\int_{\bar{\omega}^{j}}^{\infty} \omega R_{t+1}^{k} Q_{t} K_{t+1}^{j} \mathrm{~d} F(\omega)-\left(1-F\left(\bar{\omega}^{j}\right)\right) \bar{\omega}^{j} R_{t+1}^{k} Q_{t} K_{t+1}^{j}\right\},
$$

where expectations are taken with respect to the random variable, $R_{t+1}^{k}$, and it is understood that $\bar{\omega}^{j}$ may be made contingent on the realization of this variable. Combining this relation with Equation (3.5) allows us to simplify the entrepreneur's objective to maximization of

$$
E\left\{\left[1-\mu \int_{0}^{\bar{\omega}^{j}} \omega \mathrm{d} F(\omega)\right] U_{t+1}^{r k}\right\} E\left\{R_{t+1}^{k}\right\} Q_{t} K_{t+1}^{j}-R_{t+1}\left(Q_{t} K_{t+1}^{j}-N_{t+1}^{j}\right)
$$

where $U_{t+1}^{r k} \equiv R_{t+1}^{k} / E\left\{R_{t+1}^{k}\right\}$ is the ratio of the realized return to capital to the expected return. Given that the intermediary must receive a competitive return, the entrepreneur internalizes the expected default costs, as Equation (3.7) suggests.

The formal investment and contracting problem then reduces to choosing $K_{t+1}^{j}$ and a schedule for $\bar{\omega}^{j}$ (as a function of the realized values of $R_{t+1}^{k}$ ) to maximize Equation (3.7), subject to the set of state-contingent constraints implied by Equation (3.5). The distributions of the aggregate and idiosyncratic risks to the return to capital, the price of capital, and the quantity of net worth that the entrepreneur brings to the table are taken as given in the maximization.

Let $s_{t} \equiv E\left\{R_{t+1}^{k} / R_{t+1}\right\}$ be the expected discounted return to capital. For entrepreneurs to purchase capital in the competitive equilibrium it must be the case that $s_{t} \geqslant 1$. Given $s_{t} \geqslant 1$, the first-order necessary conditions yield the following relation for optimal capital purchases (see Appendix A for details):

$$
Q_{t} K_{t+1}^{j}=\psi\left(s_{t}\right) N_{i+1}^{j}, \quad \text { with } \quad \psi(1)=1, \psi^{\prime}(\cdot)>0
$$

Equation (3.8) describes the critical link between capital expenditures by the firm and financial conditions, as measured by the wedge between the expected the return to capital and the safe rate, $s_{t}$, and by entrepreneurial net worth, $N_{i+1}^{j}{ }^{11}$. Given the value of $K_{t+1}^{j}$ that satisfies Equation (3.8), the schedule for $\bar{\omega}^{j}$ is pinned down uniquely by the state-contingent constraint on the expected return to debt, defined by Equation (3.5).

Equation (3.8) is a key relationship in the model: It shows that capital expenditures by each firm are proportional to the net worth of the owner/entrepreneur, with a proportionality factor that is increasing in the expected discounted return to capital, $s_{i}$. Everything else equal, a rise in the expected discounted return to capital reduces the expected default probability. As a consequence, the entrepreneur can take on more

II In the costly enforcement model of Kiyotaki and Moore (1997), $\psi(\cdot)=1$, implying $Q_{t} K_{i+1}=N_{t+1}$. 


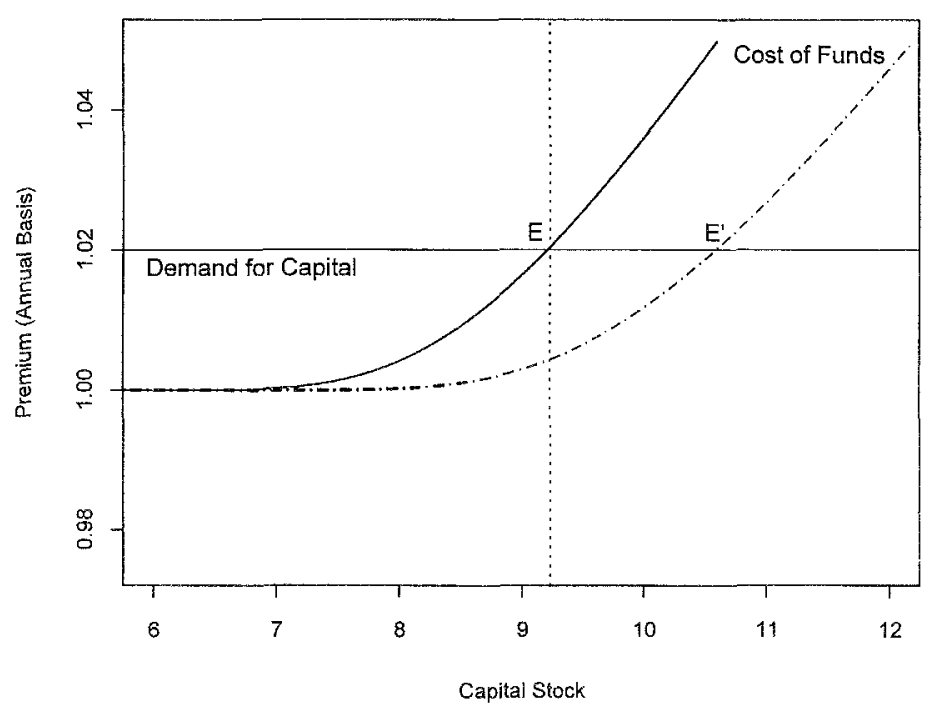

Fig. 1. Effect of an increase in net worth.

debt and expand the size of his firm. He is constrained from raising the size of the firm indefinitely by the fact that expected default costs also rise as the ratio of borrowing to net worth increases.

An equivalent way of expressing Equation (3.8) is

$$
E\left\{R_{t+1}^{k}\right\}=s\left(\frac{N_{t+1}^{j}}{Q_{t} K_{t+1}^{j}}\right) R_{t+1}, \quad s^{\prime}(\cdot)<0 .
$$

For an entrepreneur who is not fully self-financed, in equilibrium the return to capital will be equated to the marginal cost of external finance. Thus Equation (3.9) expresses the equilibrium condition that the ratio $s$ of the cost of external finance to the safe rate - which we have called the discounted return to capital but may be equally well interpreted as the external finance premium - depends inversely on the share of the firm's capital investment that is financed by the entrepreneur's own net worth.

Figure 1 illustrates this relationship using the actual contract calibrated for model analysis in the next section. Firm $j$ 's demand for capital is on the horizontal axis and the cost of funds normalized by the safe rate of return is on the vertical axis. For capital stocks which can be financed entirely by the entrepreneur's net worth, in this case $K<4.6$, the firm faces a cost of funds equal to the risk free rate. As capital acquisitions rise into the range where external finance is necessary, the costof-funds curve becomes upward sloping, reflecting the increase in expected default costs associated with the higher ratio of debt to net worth. While the supply of funds curve is upward sloping, owing to constant returns to scale, the demand for capital is horizontal at an expected return 2 percentage points above the risk free rate. 
Point $\mathrm{E}$, where the firm's marginal cost of funds equals the expected return to capital yields the optimal choice of the capital stock $K=9.2$. For this contract, the leverage ratio is $50 \%$.

It is easy to illustrate how a shift in the firm's financial position affects its demand for capital. A $15 \%$ increase in net worth, $N_{t+l}^{j}$, for example, causes the rightward shift in the cost-of-funds curve depicted by the hatched line in Figure 1. At the old level of capital demand, the premium for external finance declines: The rise in net worth relative to the capital stock reduces the expected default probability, everything else equal. As a consequence, the firm is able to expand capacity to point $E^{\prime}$. Similarly, a decline in net worth reduces the firm's effective demand for capital.

In the next section we incorporate this firm-level relation into a general equilibrium framework. Before proceeding, however, we note that, in general, when the firm's demand for capital depends on its financial position, aggregation becomes difficult. The reason is that, in general, the total demand for capital will depend on the distribution of wealth across firms. Here, however, the assumption of constant returns to scale throughout induces a proportional relation between net worth and capital demand at the firm level; further, the factor of proportionality is independent of firm-specific factors. Thus it is straightforward to aggregate Equation (3.8) to derive a relationship between the total demand for capital and the total stock of entrepreneurial net worth.

\section{General equilibrium}

We now embed the partial equilibrium contracting problem between the lender and the entrepreneur within a dynamic general equilibrium model. Among other things, this will permit us to endogenize the safe interest rate, the return to capital, and the relative price of capital, all of which were taken as given in the partial equilibrium.

We proceed in several steps. First we characterize aggregate behavior for the entrepreneurial sector. From this exercise we obtain aggregate demand curves for labor and capital, given the real wage and the riskless interest rate. The market demand for capital is a key component of the model since it reflects the impact of financial market imperfections. We also derive how the aggregate stock of entrepreneurial net worth, an important state variable determining the demand for capital, evolves over time.

We next place our "non-standard" entrepreneurial sector within a conventional Dynamic New Keynesian framework. To do so, we add to the model both households and retailers, the latter being included only in order to introduce price inertia in a tractable manner. We also add a government sector that conducts fiscal and monetary policies. Since much of the model is standard, we simply write the log-linearized framework used for computations and defer a more detailed derivation to Appendix $B$. Expressing the model in a log-linearized form makes the way in which the financial accelerator influences business cycle dynamics reasonably transparent. 


\subsection{The entrepreneurial sector}

Recall that entrepreneurs purchase capital in each period for use in the subsequent period. Capital is used in combination with hired labor to produce (wholesale) output. We assume that production is constant returns to scale, which allows us to write the production function as an aggregate relationship. We specify the aggregate production function relevant to any given period $t$ as

$$
Y_{t}=A_{t} K_{t}^{\alpha} L_{t}^{1-\alpha}
$$

where $Y_{t}$ is aggregate output of wholesale goods, $K_{t}$ is the aggregate amount of capital purchased by entrepreneurs in period $t-1, L_{t}$ is labor input, and $A_{t}$ is an exogenous technology parameter.

Let $I_{t}$ denote aggregate investment expenditures. The aggregate capital stock evolves according to

$$
K_{t+1}=\Phi\left(\frac{I_{t}}{K_{t}}\right) K_{t}+(1-\delta) K_{t}
$$

where $\delta$ is the depreciation rate. We assume that there are increasing marginal adjustment costs in the production of capital, which we capture by assuming that aggregate investment expenditures of $I_{t}$ yield a gross output of new capital goods $\Phi\left(I_{l} / K_{t}\right) K_{t}$, where $\Phi(\cdot)$ is increasing and concave and $\Phi(0)=0$. We include adjustment costs to permit a variable price of capital. As in Kiyotaki and Moore (1997), the idea is to have asset price variability contribute to volatility in entrepreneurial net worth. In equilibrium, given the adjustment cost function, the price of a unit of capital in terms of the numeraire good, $Q_{t}$, is given by ${ }^{12}$

$$
Q_{t}=\left[\Phi^{\prime}\left(\frac{I_{t}}{K_{t}}\right)\right]^{-1}
$$

We normalize the adjustment cost function so that the price of capital goods is unity in the steady state.

Assume that entrepreneurs sell their output to retailers. Let $1 / X_{t}$ be the relative price of wholesale goods. Equivalently, $X_{t}$ is the gross markup of retail goods over wholesale

\footnotetext{
12 To implement investment expenditures in the decentralized equilibrium, think of there being

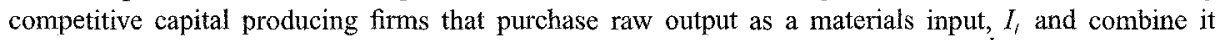
with rented capital, $K_{t}$ to produce new capital goods via the production function $\Phi\left(\frac{l_{t}}{K_{t}}\right) K_{t}$. These capital goods are then sold at the price $Q_{t}$. Since the capital-producing technology assumes constant returns to scale, these capital-producing firms earn zero profits in equilibrium. Equation (4.3) is derived from the first-order condition for investment for one of these firms.
} 
goods. Then the Cobb-Douglas production technology implies that the rent paid to a unit of capital in $t+1$ (for production of wholesale goods) is ${ }^{13}$

$$
\frac{1}{X_{t+1}} \frac{\alpha Y_{t+1}}{K_{t+1}}
$$

The expected gross return to holding a unit of capital from $t$ to $t+1$ can be written

$$
E\left\{R_{t+1}^{k}\right\}=E\left\{\frac{\frac{1}{X_{t+1}} \frac{\alpha Y_{t+1}}{K_{t+1}}+Q_{t+1}(1-\delta)}{Q_{t}}\right\}
$$

Substitution of Equations (4.1) and (4.3) into Equation (4.4) yields a reasonably conventional demand curve for new capital. As usual, the return on capital depends inversely on the level of investment, reflecting diminishing returns.

The supply curve for investment finance is obtained by aggregating Equation (3.8) over firms, and inverting to obtain:

$$
E\left\{R_{t+1}^{k}\right\}=s\left(\frac{N_{t+1}}{Q_{t} K_{t+1}}\right) R_{t+1} .
$$

As in Equation (3.9), the function $s(\cdot)$ is the ratio of the costs of external and internal finance; it is decreasing in $N_{t+1} / Q_{t} K_{t+1}$ for $N_{t+1}<Q_{t} K_{t+1}$. The unusual feature of this supply curve, of course, is the dependence of the cost of funds on the aggregate financial condition of entrepreneurs, as measured by the ratio $N_{t+1} / Q_{t} K_{t+1}$.

The dynamic behavior of capital demand and the return to capital depend on the evolution of entrepreneurial net worth, $N_{t+1}, N_{t+1}$ reflects the equity stake that entrepreneurs have in their firms, and accordingly depends on firms' earnings net of interest payments to lenders. As a technical matter, however, it is necessary to start entrepreneurs off with some net worth in order to allow them to begin operations. Following Bernanke and Gertler (1989) and Carlstrom and Fuerst (1997), we assume

13 To be consistent with our assumption that adjustment costs are external to the firm, we assume that entrepreneurs sell their capital at the end of period $t+1$ to the investment sector at price $\bar{Q}_{t+1}$. Thus capital is then used to produce new investment goods and resold at the price $Q_{t+1}$. The "rental rate" $\left(\bar{Q}_{t+1}-Q_{t+1}\right)$ reflects the influence of capital accumulation on adjustment costs. This rate is determined by the zero-profit condition

$$
Q_{t} \Phi\left(\frac{I_{t}}{K_{t}}\right)-\frac{I_{t}}{K_{t}}-\left(\bar{Q}_{t}-Q_{t}\right)=0
$$

In steady state $\Phi\left(\frac{t_{t}}{K^{i}}\right)=\delta$ and $\tilde{\Phi}^{\prime}\left(\frac{t_{t}}{K_{t}}\right)=1$, implying that $\bar{Q}=Q=1$. Around the steady state, the difference between $\bar{Q}_{t+1}$ and $Q_{t}$ is second order. We therefore omit the rental term and express Equation (4.4) using $Q_{t+1}$ rather than $\bar{Q}_{t+1}$. 
that, in addition to operating firms, entrepreneurs supplement their income by working in the general labor market. Total labor input $L_{t}$ is taken to be the following composite of household labor, $H_{t}$, and "entrepreneurial labor", $H_{t}^{e}$ :

$$
L_{t}=H_{t}^{\Omega}\left(H_{i}^{e}\right)^{1-\Omega}
$$

We assume further that entrepreneurs supply their labor inelastically, and we normalize total entrepreneurial labor to unity ${ }^{14}$. In the calibrations below we keep the share of income going to entrepreneurial labor small (on the order of .01), so that this modification of the standard production function does not have significant direct effects on the results.

Let $V_{t}$ be entrepreneurial equity (i.e., wealth accumulated by entrepreneurs from operating firms), let $W_{t}^{e}$ denote the entrepreneurial wage, and let $\bar{\omega}_{t}$ denote the statecontingent value of $\bar{\omega}$ set in period $t$. Then aggregate entrepreneurial net worth at the end of period $t, N_{t+1}$, is given by

$$
N_{t+1}=\gamma V_{t}+W_{t}^{e}
$$

with

$$
V_{t}=R_{t}^{k} Q_{t-1} K_{t}-\left(R_{t}+\frac{\mu \int_{0}^{\overline{\omega_{t}}} \omega R_{t}^{k} Q_{t-1} K_{t} \mathrm{~d} F(\omega)}{Q_{t-1} K_{t}-N_{t-1}}\right)\left(Q_{t-1} K_{t}-N_{t-1}\right)
$$

where $\gamma V_{t}$ is the equity held by entrepreneurs at $t-1$ who are still in business at $t$. (Entrepreneurs who fail in $t$ consume the residual equity $(1-\gamma) V_{t}$. That is, $C_{t}^{e}=(1-\gamma) V_{t}$.) Entrepreneurial equity equals gross earnings on holdings of equity from $t-1$ to $t$ less repayment of borrowings. The ratio of default costs to quantity borrowed,

$$
\frac{\mu \int_{0}^{\bar{\omega}_{t}} \omega R_{t}^{k} Q_{t-1} K_{t} \mathrm{~d} F(\omega)}{Q_{t-1} K_{t}-N_{t-1}}
$$

reflects the premium for external finance.

Clearly, under any reasonable parametrization, entrepreneurial equity provides the main source of variation in $N_{t+l}$. Further, this equity may be highly sensitive to unexpected shifts in asset prices, especially if firms are leveraged. To illustrate, let $U_{t}^{r k} \equiv R_{t}^{k}-E_{l-1}\left\{R_{t}^{k}\right\}$ be the unexpected shift in the gross return to capital, and let

14 Note that cntrepreneurs do not have to work only on their own projects (such an assumption would violate aggregate returns to scale, given that individual projects can be of different sizes). 
$U_{t}^{d p} \equiv \int_{0}^{\bar{\omega}_{t}} \omega Q_{t-1} K_{t} \mathrm{~d} F(\omega)-E_{t-1}\left\{\int_{0}^{\bar{\omega}_{t}} \omega Q_{t-1} K_{t} \mathrm{~d} F(\omega)\right\}$ be the unexpected shift in the conditional (on the aggregate state) default costs. We can express $V_{t}$ as

$$
V_{t}=\left[U_{t}^{r k}\left(1-\mu U_{t}^{d p}\right)\right] Q_{t-1} K_{t}+E_{t-1}\left\{V_{l}\right\}
$$

Now consider the impact of a unexpected increase in the ex post return to capital. Differentiating Equation (4.9) yields an expression for the elasticity of entrepreneurial equity with respect to an unanticipated movement in the return to capital:

$$
\frac{\partial V_{t} / E_{t-1}\left\{V_{t}\right\}}{\partial U_{t}^{r k} / E_{t-1}\left\{R_{t}^{k}\right\}}=\frac{E_{t-1}\left\{R_{t}^{k}\right\} Q_{t-1} K_{t}}{E_{t-1}\left\{V_{t}\right\}} \geqslant 1 .
$$

According to Equation (4.10), an unexpected one percent change in the ex post return to capital leads to a percentage change in entrepreneurial equity equal to the ratio of gross holdings of capital to equity. To the extent that entrepreneurs are leveraged, this ratio exceeds unity, implying a magnification effect of unexpected asset returns on entrepreneurial equity. The key point here is that unexpected movements in asset prices, which are likely the largest source of unexpected movements in gross returns, can have a substantial effect on firms' financial positions.

In the general equilibrium, further, there is a kind of multiplier effect, as we shall see. An unanticipated rise in asset prices raises net worth more than proportionately, which stimulates investment and, in turn, raises asset prices even further. And so on. This phenomenon will become evident in the model simulations.

We next obtain demand curves for household and entrepreneurial labor, found by equating marginal product with the wage for each case:

$$
\begin{aligned}
& (1-\alpha) \Omega \frac{Y_{t}}{H_{t}}=X_{t} W_{t}, \\
& (1-\alpha)(1-\Omega) \frac{Y_{t}}{H_{l}^{e}}=X_{t} W_{t}^{e},
\end{aligned}
$$

where $W_{t}$ is the real wage for household labor and $W_{t}^{e}$ is the real wage for entrepreneurial labor.

Combining Equations (4.1), (4.7), (4.8), and (4.12) and imposing the condition that entrepreneurial labor is fixed at unity, yields a difference equation for $N_{t+1}$ :

$$
\begin{aligned}
N_{t+1}= & \gamma\left[R_{t}^{k} Q_{t-1} K_{t}-\left(R_{t}+\frac{\mu \int_{0}^{\overline{\omega_{t}}} \omega \mathrm{d} F(\omega) R_{t}^{k} Q_{t-1} K_{t}}{Q_{t-1} K_{t}-N_{t}}\right)\left(Q_{t-1} K_{t}-N_{t}\right)\right] \\
& +(1-\alpha)(1-\Omega) A_{t} K_{t}^{\alpha} H_{t}^{(1-\alpha) \Omega}
\end{aligned}
$$

Equation (4.13) and the supply curve for investment funds, Equation (4.5), are the two basic ingredients of the financial accelerator. The latter equation describes how 
movements in net worth influence the cost of capital. The former characterizes the endogenous variation in net worth.

Thus far we have determined wholesale output, investment and the evolution of capital, the price of capital, and the evolution of net worth, given the riskless real interest rate $R_{t+1}$, the household real wage $W_{t}$, and the relative price of wholesale goods $1 / X_{t}$. To determine these prices and complete the model, we need to add the household, retail, and government sectors.

\subsection{The complete log-linearized model}

We now present the complete macroeconomic framework. Much of the derivation is standard and not central to the development of the financial accelerator. We therefore simply write the complete log-linearized model directly, and defer most of the details to Appendix B.

As we have emphasized, the model is a DNK framework modified to allow for a financial accelerator. In the background, along with the entrepreneurs we have described are households and retailers. Households are infinitely-lived agents who consume, save, work, and hold monetary and nonmonetary assets. We assume that household utility is separable over time and over consumption, real money balances, and leisure. Momentary utility, further, is logarithmic in each of these arguments ${ }^{15}$.

As is standard in the literature, to motivate sticky prices we modify the model to allow for monopolistic competition and (implicit) costs of adjusting nominal prices. It is inconvenient to assume that the entrepreneurs who purchase capital and produce output in this model are monopolistically competitive, since that assumption would complicate the analyses of the financial contract with lenders and of the evolution of net worth. To avoid this problem, we instead assume that the monopolistic competition occurs at the "retail" level. Specifically, we assume there exists a continuum of retailers (of measure one). Retailers buy output from entrepreneur-producers in a competitive market, then slightly differentiate the output they purchase (say, by painting it a unique color or adding a brand name) at no resource cost. Because the product is differentiated, each retailer has a bit of market power. Households and firms then purchase CES aggregates of these retail goods. It is these CES aggregates that are converted into consumption and investment goods, and whose price index defines the aggregate price level. Profits from retail activity are rebated lump-sum to households (i.e., households are the ultimate owners of retail outlets.)

To introduce price inertia, we assume that a given retailer is free to change his price in a given period only with probability $1-\theta$. The expected duration of any price change is $\frac{1}{1-\theta}$. This device, following Calvo (1983), provides a simple way to incorporate staggered long-term nominal price setting. Because the probability of changing price is independent of history, the aggregation problem is greatly simplified. One extra

15 In particular, household utility is given by $E_{t}\left\{\sum_{k-0} \beta^{h}\left[\ln \left(C_{i+k}\right)+\xi \ln \left(M_{t+k} / P_{t+k}\right)+\xi \ln \left(1 \cdots H_{t+k}\right)\right]\right\}$. 
twist, following Bernanke and Woodford (1997), is that firms setting prices at $t$ are assumed to do so prior to the realization of any aggregate uncertainty at time $t$.

Let lower case variables denote percent deviations from the steady state, and let ratios of capital letters without time subscript denotes the steady state value of the respective ratio. Further, let $\phi_{t}^{z}$ denote a collection of terms of second-order importance in the equation for any variable $z$, and let $\varepsilon_{t}^{z}$ be an i.i.d. disturbance to the equation for variable $z$. Finally, let $G_{t}$ denote government consumption, $\pi_{t} \equiv p_{t}-p_{t-1}$ the rate of inflation from $t-1$ to $t$, and $r_{t+1}^{n} \equiv r_{t+1}+E\left\{p_{t+1}-p_{t}\right\}$ be the nominal interest rate. It is then convenient to express the complete log-linearized model in terms of four blocks of equations: (1) aggregate demand; (2) aggregate supply; (3) evolution of the state variables; and (4) monetary policy rule and shock processes. Appendix B provides details.

(1) Aggregate demand

$$
\begin{aligned}
& y_{t}=\frac{C}{Y} c_{t}+\frac{I}{Y} i_{t}+\frac{G}{Y} g_{t}+\frac{C^{e}}{Y} c_{t}^{e}+\cdots+\phi_{t}^{v}, \\
& c_{t}=-r_{t+1}+E_{t}\left\{c_{t+1}\right\}, \\
& c_{t}^{e}=n_{t+1}+\cdots+\phi_{t}^{c^{e}}, \\
& E_{t}\left\{r_{t+1}^{k}\right\}-r_{t+1}=-v\left[n_{t+1}-\left(q_{t}+k_{t+1}\right)\right], \\
& r_{t+1}^{k}=(1-\epsilon)\left(y_{t+1}-k_{t+1}-x_{t+1}\right)+\epsilon q_{t+1}-q_{t}, \\
& q_{t}=\varphi\left(i_{t}-k_{t}\right) .
\end{aligned}
$$

(2) Aggregate Supply

$$
\begin{aligned}
& y_{t}=a_{t}+\alpha k_{t}+(1-\alpha) \Omega h_{t}, \\
& y_{t}-h_{t}-x_{t}-c_{t}=\eta^{-1} h_{t}, \\
& \pi_{t}=E_{t-1}\left\{\kappa\left(-x_{t}\right)+\beta \pi_{t+1}\right\} .
\end{aligned}
$$

\section{(3) Evolution of State Variables}

$$
\begin{aligned}
& k_{t+1}=\delta i_{t}+(1-\delta) k_{i}, \\
& n_{t+1}=\frac{\gamma R K}{N}\left(r_{t}^{k} \cdots r_{t}\right)+r_{t}+n_{t}+\cdots \phi_{t}^{n} .
\end{aligned}
$$




\section{(4) Monetary Policy Rule and Shock Processes}

$$
\begin{aligned}
& r_{t}^{n}=\rho r_{t-1}^{n}+\varsigma \pi_{t-1}+\varepsilon_{t}^{\prime n}, \\
& g_{t}=\rho_{g} g_{t-1}+\varepsilon_{t}^{g}, \\
& a_{t}=\rho_{a} a_{t-1}+\varepsilon_{t}^{a},
\end{aligned}
$$

with

$$
\begin{aligned}
\phi_{t}^{y} & \equiv \frac{D K}{Y}\left[\log \left(\mu \int_{0}^{\omega_{t}} \omega \mathrm{d} F(\omega) R_{t}^{k} Q_{t-1} K_{t} / D K\right)\right], \\
D & \equiv \mu \int_{0}^{\bar{\omega}} \omega \mathrm{d} F(\omega) R^{k} \\
\phi_{t}^{c^{e}} & =\log \left(\frac{1-C_{t+1}^{e} / N_{t+1}}{1-C^{e} / N}\right), \\
\phi_{t}^{n} & \equiv \frac{\left(R^{k} / R-1\right) K}{N}\left(r_{t}^{k}+q_{t-1}+k_{t}\right)+\frac{(1-\alpha)(1-\Omega)(Y / X)}{N} y_{t}-x_{t}, \\
v & \equiv \frac{\psi\left(R^{k} / R\right)}{\psi^{\prime}\left(R^{k} / R\right)}, \quad \epsilon \equiv \frac{1-\delta}{(1-\delta)+\alpha Y /(X K)}, \\
\varphi & \equiv \frac{\left(\Phi(I / K)^{-1}\right)^{\prime}}{\left(\Phi(I / K)^{-1}\right)^{\prime \prime}}, \quad \kappa \equiv\left(\frac{1-\theta}{\theta}\right)(1-\theta \beta) .
\end{aligned}
$$

Equation (4.14) is the $\log$-linearized version of the resource constraint. The primary determinants of the variation in aggregate expenditures $y_{t}$ are household consumption $c_{t}$, investment $i_{t}$, and government consumption $g_{t}$. Of lesser importance is variation in entrepreneurial consumption $c_{t}^{e}{ }^{16}$. Finally, variation in resources devoted monitoring cost, embedded in the term $\phi_{t}^{y}$, also matters in principle. Under reasonable parametrizations, however, this factor has no perceptible impact on dynamics.

Household consumption is governed by the consumption Euler relation, given by Equation (4.15). The unit coefficient on the real interest rate (i.e., the intertemporal elasticity of substitution) reflects the assumption of logarithmic utility over consumption. By enforcing the standard consumption Euler equation, we are effectively assuming that financial market frictions do not impede household behavior. Numerous authors have argued, however, that credit constraints at the household level influence a non-trivial portion of aggregate consumption spending. An interesting extension of

\footnotetext{
16 Note that each variable in the log-linearized resource constraint is weighted by the variable's share of output in the steady state. Under any reasonable parametrization of the model, $c_{i}^{e}$ has a relatively low weight.
} 
this model would be to incorporate household borrowing and associated frictions. With some slight modification, the financial accelerator would then also apply to household spending, strengthening the overall effect.

Since entrepreneurial consumption is a (small) fixed fraction of aggregate net worth (recall that entrepreneurs who retire simply consume their assets), it simply varies proportionately with aggregate net worth, as Equation (4.16) indicates.

Equations (4.17), (4.18), and (4.19) characterize investment demand. They are the log-linearized versions of Equations (4.5), (4.4) and (4.3), respectively. Equation (4.17), in particular, characterizes the influence of net worth on investment. In the absence of capital market frictions, this relation collapses to $E_{t}\left\{r_{t+1}^{k}\right\}-r_{t+1}=0$ : Investment is pushed to the point where the expected return on capital, $E_{t}\left\{r_{t+1}^{k}\right\}$, equals the opportunity cost of funds $r_{t+1}{ }^{17}$. With capital market frictions present, however, the cost of external funds depends on entrepreneurs' percentage equity holding, i.e., net worth relative to the gross value of capital, $n_{t+1}-\left(q_{t}+k_{t+1}\right)$. A rise in this ratio reduces the cost of external funds, implying that investment will rise. While Equation (4.17) embeds the financial accelerator, Equations (4.18) and (4.19) are conventional (loglinearized) relations for the marginal product of capital and the link between asset prices and investment.

Equations (4.20), (4.21) and (4.22) constitute the aggregate supply block. Equation (4.20) is the linearized version of the production function (4.1), after incorporating the assumption that the supply of entrepreneurial labor is fixed. Equation (4.21) characterizes labor market equilibrium. The left side is the marginal product of labor weighted by the marginal utility of consumption ${ }^{18}$. In equilibrium, it varies proportionately with the markup of retail goods over wholesale goods (i.e., the inverse of the relative price of wholesale goods.)

Equation (4.22) characterizes price adjustment, as implied by the staggered price setting formulation of Calvo (1983) that we described earlier [along with the modification suggested by Bernanke and Woodford (1997)]. This equation has the flavor of a traditional Phillips curve, once it is recognized that the markup $x_{t}$ varies inversely with the state of demand. With nominal price rigidities, the retail firms that hold their prices fixed over the period respond to increased demand by selling more. To accommodate the rise in sales they increase their purchases of wholesale goods from entrepreneurs, which bids up the relative wholesale price and bids down the markup. It is for this reason that $-x_{t}$ provides a measure of demand when prices are sticky. In turn, the sensitivity of inflation to demand depends on the degree of price inertia: The slope coefficient $\kappa$ can be shown to be decreasing in $\theta$, the probability an individual price stays fixed from period to period. One difference between Equation (4.22) and

\footnotetext{
${ }^{17}$ In the absence of capital market frictions, the first-order condition from the entrepreneur's partial equilibrium capital choice decision yields $E\left\{R_{t+1}^{k}\right\}=R_{t+1}$. In this instance if $E\left\{R_{t+1}^{k}\right\}>R_{t+1}$, the entrepreneur would buy an infixite amount of capital, and if $E\left\{R_{t+1}^{k}\right\}<R_{t+1}$, he would buy none. When $E\left\{R_{t+1}^{k}\right\}=R_{t+1}$, he is indifferent about the scale of operation of his firm.

${ }^{18}$ Given logarithmic preferences, the marginal utility of consumption is simply $-c_{l}$.
} 
a traditional expectations-augmented Phillips curve is that it involves expected future inflation as opposed to expected current inflation. This alteration reflects the forwardlooking nature of price setting ${ }^{19}$.

Equations (4.23) and (4.24) are transition equations for the two state variables, capital $k_{t}$ and net worth $n_{t}$. The relation for capital, Equation (4.23), is standard, and is just the linearized version of Equation (4.2). The evolution of net worth depends primarily on the net return to entrepreneurs on their equity stake, given by the first term, and on the lagged value of net worth. Note again that a one percent rise in the return to capital relative to the riskless rate has a disproportionate impact on net worth due to the leverage effect described in the previous section. In particular, the impact of $r_{t}^{k}-r_{t}$ on $n_{t+1}$ is weighted by the coefficient $\gamma R K / N$, which is the ratio of gross capital holdings to entrepreneurial net worth.

How the financial accelerator augments the conventional DNK model should now be fairly transparent. Net worth affects investment through the arbitrage Equation (4.17). Equation (4.24) then characterizes the evolution of net worth. Thus, among other things, the financial accelerator adds another state variable to the model, enriching the dynamics. All the other equations of the model are conventional for the DNK framework [particularly King and Wolman's (1996) version with adjustment costs of capital].

Equation (4.25) is the monetary policy rule ${ }^{20}$. Following conventional wisdom, we take the short-term nominal interest rate to be the instrument of monetary policy. We consider a simple rule, according to which the central bank adjusts the current nominal interest rate in response to the lagged inflation rate and the lagged interest rate. Rules of this form do a reasonably good job of describing the variation of short term interest rates [see Clarida, Gali and Gertler (1997)]. We also considered variants that allow for responses to output as well as inflation, in the spirit of the Taylor (1993) rule. Obviously, the greater the extent to which monetary policy is able to stabilize output, the smaller is the role of the financial accelerator to amplify and propagate business cycles, as would be true for any kind of propagation mechanism. With the financial accelerator mechanism present, however, smaller countercyclical movements in interest rates are required to dampen output fluctuations.

Finally, Equations (4.26) and (4.27) impose that the exogenous disturbances to government spending and technology obey stationary autoregressive processes.

We next consider two extensions of the model.

19 Iterating Equation (4.22) forward yields $\pi_{t}=\sum_{k=0}^{\infty} \beta^{k} \kappa\left(p_{t+k}^{w}-p_{t+k}\right)$. With forward-looking price setting, how fast prices adjust depends on the expected discounted stream of future demand.

20 The interest rate rule may be thought of as a money supply equation. The associated money demand equation is given by $m_{t}-p_{t}=c_{t}-\left(\frac{1}{R^{n}}\right) r_{t+1}^{n}$. Note that under interest-rate targeting this relation simply determines the path of the nominal money stock. To implement its choice of the nominal interest rate, the central bank adjusts the money stock to satisfy this equation. 


\subsubsection{Two extensions of the baseline model}

Two modifications that we consider are: (1) allowing for delays in investment; and (2) allowing for firms with differential access to credit. The first modification permits the model to generate the kind of hump-shaped output dynamics that are observed in the data. The second is meant to increase descriptive realism.

4.2.1.1. Investment delays. Disturbances to the economy typically appear to generate a delayed and hump-shaped response of output. A classic example is the output response to a monetary policy shock [see, e.g., Christiano, Eichenbaum and Evans (1996) and Bernanke and Mihov (1998)]. It takes roughly two quarters before an orthogonalized innovation in the federal funds rate, for example, generates a significant movement in output. The peak of the output response occurs well after the peak in the funds rate deviation. Rotemberg and Woodford (1997) address this issue by assuming that consumption expenditures are determined two periods in advance (in a model in which non-durable consumption is the only type of private expenditure). We take an approach that is similar in spirit, but instead assume that it is investment expenditures rather than consumption expenditures that are determined in advance.

We focus on investment for two reasons. First, the idea that investment expenditures take time to plan is highly plausible, as recently documented by Christiano and Todd (1996). Second, movements in consumption lead movements in investment over the cycle, as emphasized by Bernanke and Gertler (1995) and Christiano and Todd (1996). For example, Bernanke and Gertler (1995) show that in response to a monetary policy shock household spending responds fairly quickly, well in advance of business capital expenditures.

Modifying the model to allow for investment delays is straightforward. Suppose that investment expenditure are chosen $j$ periods in advance. Then the first-order condition relating the price of capital to investment, Equation (4.3), is modified to

$$
E_{t}\left\{Q_{i+j}-\left[\Phi^{\prime}\left(\frac{I_{t+j}}{K_{t+j}}\right)\right]^{-1}\right\}=0 .
$$

Note that the link between asset prices and investment now holds only in expectation. With the time-to-plan feature, shocks to the economy have an immediate effect on asset prices, but a delayed effect on investment and output ${ }^{21}$.

To incorporate the investment delay in the model, we simply replace Equation (4.19) with the following log-linearized version of Equation (4.28):

$$
E_{t}\left\{q_{t+j}-\varphi\left(i_{t+j}-k_{t+j}\right)\right\}=0
$$

In our simulations, we take $j=1$.

21 Asset prices move inmediately since the return to capital depends on the expected capital gain. 
4.2.1.2. Heterogeneous firms. The baseline model assumes that all firms are alike ex ante, except for initial net worth. In practice, of course, there is considerable heterogeneity among firms along many dimensions, in particular in access to credit [see, e.g., the discussion in Gertler and Gilchrist (1994)]. To see how heterogeneity affects the results, we add to our model the assumption that there are two types of firms, those that have easy access to credit, ceteris paribus, and those that (for various informational or incentive reasons, for example) have less access to credit.

To accommodate two different types of firms, we assume that there are two types of intermediate goods (one produced by each type of firm) which are combined into a single wholesale good via a CES aggregator. Production of the intermediate good is given by

$$
Y_{i t}=A_{i t} K_{i t}^{\alpha} H_{i t}^{\Omega}\left(H_{i}^{e}\right)^{(1-\alpha-\Omega)}, \quad i=1,2 .
$$

Aggregate wholesale output is composed of sectoral output according to

$$
Y_{l}=\left[a Y_{1 t}^{\rho}+(1-a) Y_{2 t}^{\rho}\right]^{(1 / \rho)} .
$$

We also assume that capital is sector-specific, and that there are costs of adjusting the capital stock within each sector:

$$
K_{i, t+1}-K_{i t}=\phi\left(I_{i t} / K_{i t}\right) K_{i t}-\delta K_{i t} .
$$

Let $j i$ denote the number of periods in advance that investment expenditures must be chosen in sector $i$ (note that the lag may differ across sectors): Then the link between asset prices and investment in each sector is given by

$$
E_{t}\left\{Q_{i, t+j i}-\left[\Phi^{\prime}\left(\frac{I_{i, t+j i}}{K_{i, t+j i}}\right)\right]^{-1}\right\}=0 .
$$

Note that the price of capital may differ across sectors, but that arbitrage requires that each sector generate the same expected return to capital

$$
E_{t}\left\{\left[R_{1, t+1}^{k}-R_{2, t+1}^{k}\right] \beta C_{t} / C_{l+1}\right\}=0
$$

where

$$
R_{i, t+1}^{k}=\left(\frac{1}{X_{t+1}} \frac{P_{i t}}{P_{t}^{W}} \frac{\alpha Y_{i, t+1}}{K_{i, t+1}}+Q_{i, t+1}(1-\delta)\right) / Q_{i},
$$

and

$$
\frac{P_{1 i}}{P_{t}^{W}}=a\left(\frac{Y_{1 t}}{Y_{t}}\right)^{\rho-1}, \quad \frac{P_{2 t}}{P_{t}^{W}}=(1-a)\left(\frac{Y_{2 t}}{Y_{t}}\right)^{\rho-1}
$$

are the relative (wholesale) prices of goods produced in sectors 1 and 2 respectively. 
As we discuss in the next section, it is easy to parametrize the model so that firms in each sector face differential costs of credit. Further, as we illustrate below, the financial accelerator can still be quite potent, even if only a portion of firms face significant capital market frictions. Indeed, there may spillover effects from constrained to nonconstrained firms.

It is straightforward to log-linearize these equations and append them to the general model. Modified will be the aggregate supply block, to allow for the two types of intermediate output, and the law of motion for capital, to allow for two distinct types of capital.

\section{Model simulations}

In this section we present the results of some quantitative experiments to illustrate how the financial accelerator influences business cycle dynamics within the DNK framework. Specifically, we consider how credit-market imperfections amplify and propagate various shocks to the economy. We also examine the effects of allowing for delays in investment and of allowing for some firms to have better access to credit market than others.

\subsection{Model parametrization}

We choose fairly standard values for the taste and technology parameters. We set the quarterly discount factor $\beta$ to 0.99 (which also pins down the steady state quarterly riskless rate, $R=\beta^{-1}$ ). We fix the labor supply elasticity, $\eta$, at 3.0 , in keeping with much of the literature ${ }^{22}$. As is also within convention, the capital share, $\alpha$, is 0.35 , and the household labor share, $(1-\alpha)(1-\Omega)$, is 0.64 . The share of income accruing to entrepreneurs' labor is accordingly equal to 0.01 . The quarterly depreciation rate for capital, $\delta$, is assigned the usual value of 0.025 . We take the steadystate share of government expenditures in total output, $G / Y$, to be 0.2 , the approximate historical average. The serial correlation parameters for the technology and government expenditure shocks, $\rho^{a}$ and $\rho^{g}$, are assumed to be 1.0 and 0.95 , respectively. Finally, the elasticity of the price of capital with respect to the investment capital ratio, $\varphi$, is taken to be 0.25 . There is no firm consensus in the literature about what this parameter value should be ${ }^{23}$. Reasonable assumptions about adjustment costs suggest that the value should lie within a range from 0.0 to 0.50 .

\footnotetext{
22 In particular, we fix average hours worked relative to total hours available at a value that, in conjunction with logarithmic preferences over leisure, generates the desired labor supply elasticity.

$23 \mathrm{King}$ and Wolman (1996) use a value of 2.0, based on estimates from aggregate data by Chirinko (1993). Because this value implies implausibly high adjustment costs, we do not use it.
} 
The non-standard parameters of our model pertain to the interplay between real and financial factors within the entrepreneurial sector ${ }^{24}$. Specifically, we choose parameters to imply the following three steady state outcomes: (1) a risk spread, $R^{k}-R$, equal to two hundred basis points, approximately the historical average spread between the prime lending rate and the six-month Treasury bill rate; (2) an annualized business failure rate, $F(\bar{\omega})$, of three percent, the approximate rate in the data; (3) a ratio of capital to net worth, $\frac{K}{N}$, of 2 (or equivalently, a leverage ratio of 0.5 ), the approximate value in the data. To obtain these steady state values we choose the "death rate" of entrepreneurs, $1-\gamma$, to be 0.0272 (quarterly), we take the idiosyncratic productivity variable, $\log (\omega)$, to be $\log$-normally distributed with variance equal to 0.28 , and we set the fraction of realized payoffs lost in bankruptcy, $\mu$, to 0.12 . We note that our choice for $\mu$ is within the reasonable set of estimates for bankruptcy $\operatorname{costs}^{25}$.

The final parameters to be selected are those related to the rate of price adjustment and to the policy rule. We let the probability a firm does not change its price within a given period, $\theta$, equal to 0.75 , implying that the average period between price adjustments is four quarters. In the policy rule, Equation (4.25), we set the autoregressive parameter, $\rho$, to 0.9 and the coefficient on inflation equal to 0.11 (implying a long-run rise in the nominal interest rate of one hundred and ten basis points in response to a permanent one hundred basis point increase in inflation.) These numbers are roughly in line with the evidence, allowing for the fact that there have been shifts in the actual feedback rule over time [see Clarida, Gali and Gertler (1997)].

\subsection{Results}

In our experiments we consider four types of aggregate shocks: (1) a monetary policy shock, (2) a technology shock, (3) a government expenditure shock, and (4) a onetime, unanticipated transfer of wealth from households to entrepreneurs. We first study the response of the economy to these shocks in our model, excluding and including the financial accelerator. We then consider the implications of allowing for investment delays and heterogeneous firms.

\subsubsection{Response to a monetary policy shock}

The first experiment we consider is a monetary policy shock, specifically an unanticipated exogenous movement in the short-term interest rate. Analyzing the response of the model economy to a monetary policy disturbance provides a good way to evaluate our framework since a lengthy literature has produced a consensus of

24 Our parameter choices here follow closely Fisher (1996) and Carlstrom and Fuerst (1997).

25 See the discussion of bankruptcy costs in Carlstrom and Fuerst (1997). They actually use a higher number than we do $(0.20$ versus 0.12$)$. 

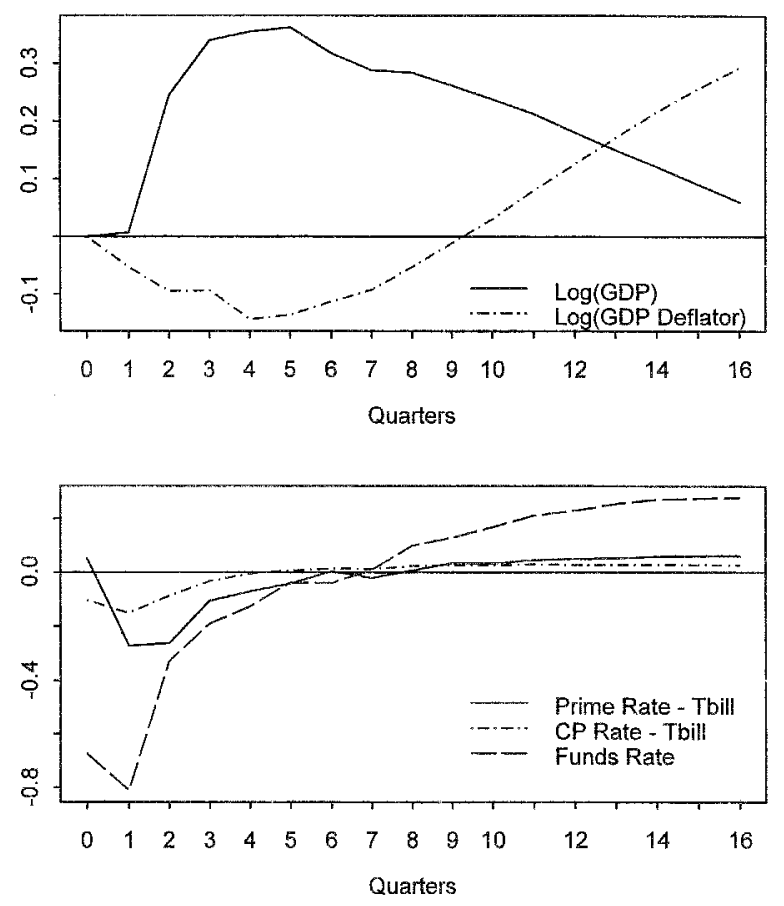

Fig. 2. Impulse response to a funds rate shock.

opinion about how the economy responds to this kind of shock ${ }^{26}$. Figure 2 summarizes this evidence, and also presents some new evidence on the behavior of several rate spread variables that proxy for premium for external funds, a key element of our model.

The results in Figure 2 are based on a five-variable quarterly VAR that includes four "standard" macroeconomic variables - the log of real GDP, the log of the GDP deflator, the $\log$ of a commodity price index, the federal funds rate - along with two rate spread variables. To identify the policy shock, we order the funds rate after the price and output variables, based on the view that monetary policy can respond contemporaneously to these variables but can affect them only with a lag. We order the spread variable after the funds rate based on the assumption that innovations in these variables do not contain any marginal information that is useful for setting current monetary policy. The two rate spread variables we consider are the difference between the six-month commercial paper rate and the six-month $\mathrm{T}$-bill rate and the difference between the prime lending rate and the six-month T-bill rate.

26 See, for example, Christiano, Eichenbaum and Evans (1996), Bernanke and Gertler (1995), Bennanke and Mihov (1998), and Leeper, Sims and Zha (1996). 
Figure 2 illustrates the impulse responses of several variables to a negative innovation in the federal funds rate. As is typically found in the literature, output declines after about two quarters, and the price level declines after about six quarters. The output decline, further, persists well after the funds rate reverts to trend. Finally, each of the spread variables rises fairly quickly, leading the downturn in output ${ }^{27}$.

Figure 3 reports the impact of the same experiment, but this time using the model economy. As in all the subsequent figures, the time units on the graphs are to be interpreted as quarters. In each picture the hatched line designates the "baseline" impulse response, generated by fixing the external finance premium at its steady state level instead of allowing it to respond to changes in the capital-net worth ratio. In other words, the baseline simulations are based on a model with the same steady state as the complete model with imperfect credit markets, but in which the additional dynamics associated with the financial accelerator have been "turned off". The solid line in each picture indicates the response observed in the complete model, with the financial accelerator included.

The figure shows the impact of an unanticipated 25 basis point (on an annual basis) decline in the nominal interest rate. Although the addition of credit-market frictions does not substantially affect the behavior of the nominal rate of interest, it does lead to a stronger response of real variables. In particular, with the financial accelerator included, the initial response of output to a given monetary impulse is about $50 \%$ greater, and the effect on investment is nearly twice as great. Further, the persistence of the real effects is substantially greater in the presence of the credit-market factors, e.g., relative to trend, output and investment in the model with credit-market imperfections after four quarters are about where they are in baseline model after only two quarters.

The impact of the financial accelerator is mirrored in the behavior of the external finance premium, which is passive in the baseline model (by assumption) but declines sharply in the complete model, slowly reverting to trend. The unanticipated decline in the funds rate stimulates the demand for capital, which in turn raises investment and the price of capital. The unanticipated increase in asset prices raises net worth, forcing down the external finance premium, which in turn further stimulates investment. A kind of multiplier effect arises, since the burst in investment raises asset prices and net worth, further pushing up investment. Entrepreneurial net worth reverts to trend as firms leave the market, but the effect is slow enough to make the external finance premium persist below trend. This persistence in net worth and the external finance premium provides the additional source of dynamics. It is interesting to observe that the response of the spread in the model economy matches the VAR evidence reasonably well.

\footnotetext{
27 It is worth noting that the impulse response of the prime-rate spread is twice as large as the impulse response of the commercial-paper spread. Since commercial paper issuers are high quality firms, this result is consistent with our model's implication that lower-quality borrowers experience larger spread movements in response to business cycle shocks.
} 

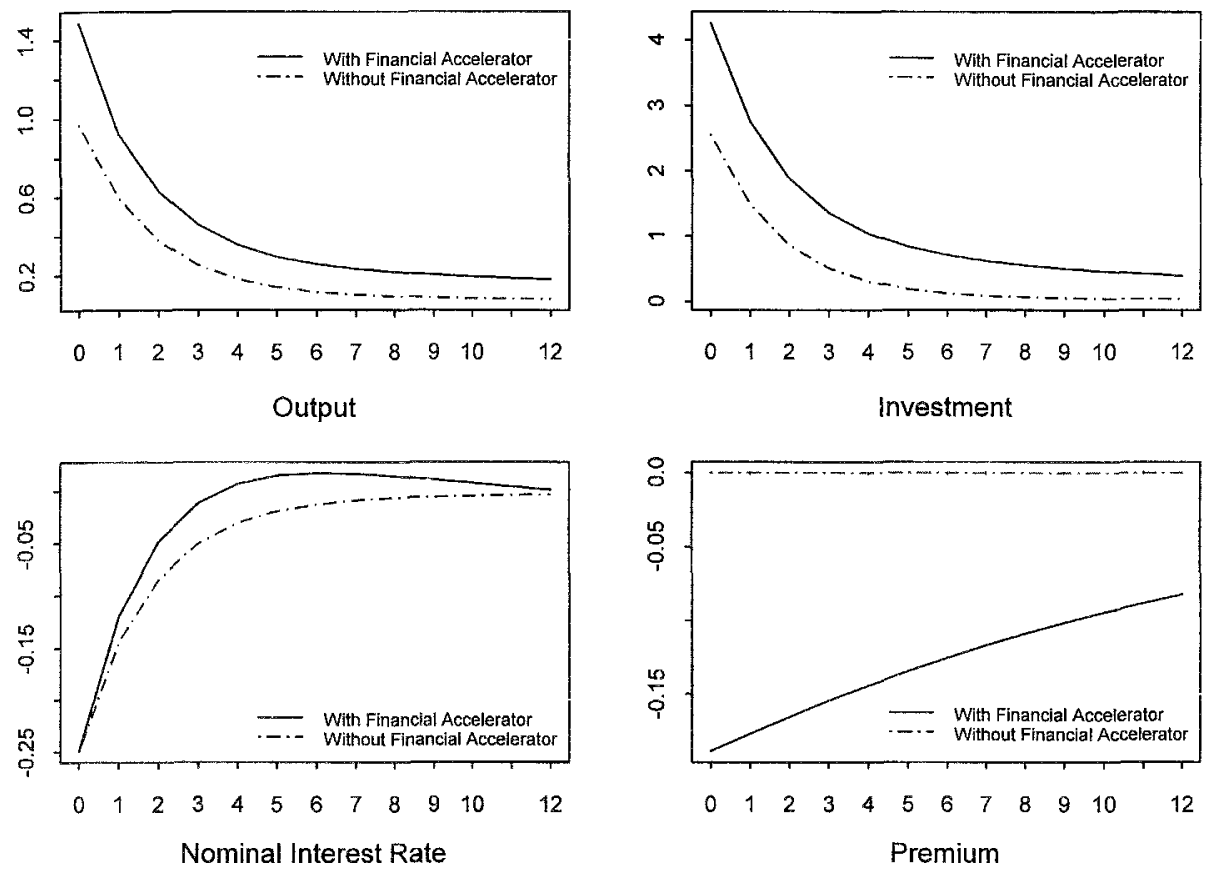

Fig. 3. Monctary shock - no investment delay. All panels: time horizon in quarters.

It is worth emphasizing that this experiment generates substantial output persistence without relying on an unusually high labor supply elasticity, as is required for the baseline model [see, e.g., the discussion in Chari, Kehoe and McGrattan (1996)]. The countercyclical movement in the premium for external funds (which is the essence of the financial accelerator) serves to flatten the marginal cost curve, as does making labor supply elastic in the baseline model.

Overall, these results lend some supports to the claims of Bernanke and Gertler (1995), that credit-market effects can help explain both the strength of the economy's response to monetary policy and the tendency for policy effects to linger even after interest rates have returned to normal. The fact that the model economy replicates the VAR evidence reasonably well is particularly encouraging. The one major point of discrepancy is that the response of output to a monetary shock is delayed in the data, but occurs immediately in the model economy ${ }^{28}$. We show shortly, however, that this problem can be fixed by allowing for investment delays.

28 It is also true that the output response is large relative to the interest rate shock. This partly reflects the high degree of intertemporal substitution embedded in the household savings decision. It may also reflect unreasonably short investrnent delays. 

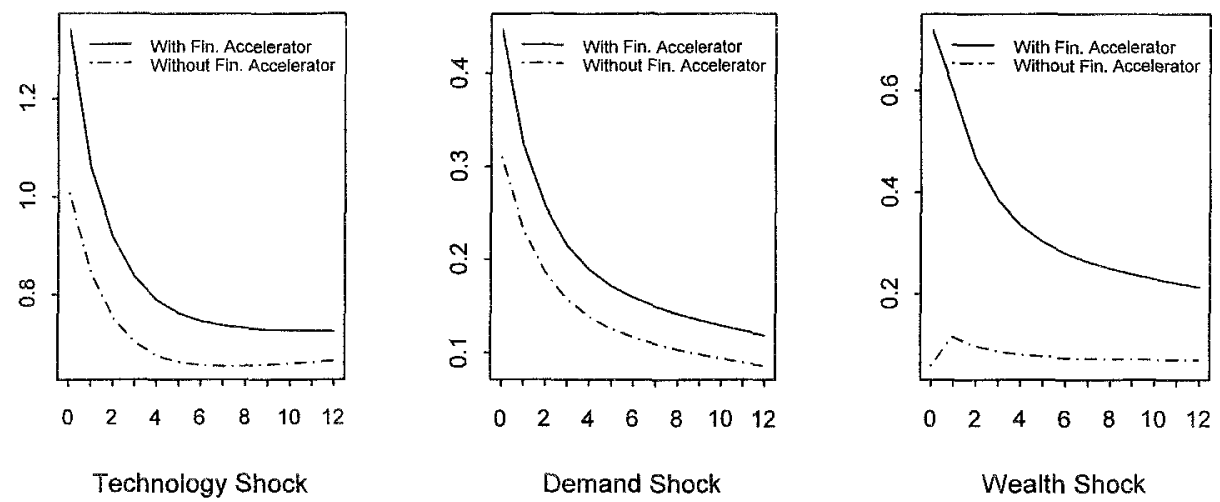

Fig. 4. Output response - alternative shocks. All panels: time horizon in quarters.

\subsubsection{Shock to technology, demand, and wealth}

Figure 4 displays the effects on output of three alternative shocks: a technology shock, a demand shock (specifically a shock to government expenditures), and a redistribution of wealth between entrepreneurs and households. Once again, the hatched lines show impulse responses from the baseline model with the financial accelerator shut off, and the solid lines show the results from the full model.

As the figure shows, the financial accelerator magnifies and propagates both the technology and demand shocks. Interestingly, the magnitude of the effects is about the same as for the monetary policy shock. Again, the central mechanism is the rise in asset prices associated with the investment boom, which raises net worth and thus reduces the external finance premium. The extra persistence comes about because net worth is slow to revert to trend.

A positive shock to entrepreneurial wealth (more precisely, a redistribution from households to entrepreneurs) has essentially no effect in the baseline model, but has both significant impact and propagation effects when credit-market frictions are present. The wealth shock portrayed is equal in magnitude to about $1 \%$ of the initial wealth of entrepreneurs and about $0.05 \%$ of the wealth of households. The transfer of wealth drives up the demand for investment goods, which raises the price of capital and thus entrepreneurs' wealth, initiating a positive feedback loop; thus, although

the exogenous shock increases entrepreneurial net worth directly by only $1 \%$, the total effect on entrepreneurs' wealth including the endogenous increase in asset prices exceeds $2 \%$. Output rises by $1 \%$ at an annual rate, and substantial persistence is generated by the slow decay of entrepreneurial net worth.

Thus the addition of credit-market effects raises the possibility that relatively small changes in entrepreneurial wealth could be an important source of cyclical fluctuations. This case is an interesting one, as it is reminiscent of (and motivated by) Fisher's (1933) "debt-deflation" argument, that redistributions between creditors and debtors arising from unanticipated price changes can have important real effects. Indeed, Fisher argued 
that this kind of mechanism accounted for the depth and protractedness of the Great Depression $^{29}$. The same kind of reasoning, further, helps explain why the recent spate of currency crises have had devastating real effects. To the extent loans from abroad are denominated in units of a foreign currency, an exchange rate collapse redistributes wealth from domestic borrowers to foreign lenders.

\subsubsection{Investment delays and heterogeneous firms}

We now suppose that investment expenditures must be planned one quarter in advance, as in Section 5.2, and consider the effect of a monetary shock. As Figure 5 illustrates, an expansionary monetary policy shock (again, an unanticipated 25 basis point decline in the funds rate) now generates a hump-shaped response of output, as in the data. This hump-shaped response is considerably more accentuated when the financial accelerator is allowed to operate. The initial response of output is still too strong, suggesting that it may be desirable to build in other types of lags. On the other hand, the persistence of the response of output is considerably greater than in the case without investment delays, and comes much closer to matching the data. Interestingly, there remains an immediate response of the external funds premium as the data suggest. The reason is that asset prices rise immediately, in anticipation of the investment boom.

We next consider the model with heterogeneous firms. We choose parameters so that firms in sector 2 face a steady-state premium for external finance of $3 \%$ per year, while firms in sector 1 face a premium of only $1 \%$. We set $a=.5125$ to generate an average steady-state premium of $2 \%$. As a consequence of this assumption, roughly half of the economy's output is produced by credit-constrained firms, a breakdown which is in accord with the rough evidence summarized in Bernanke, Gertler and Gilchrist (1996). We set $\rho=0.9$, implying that the goods produced in the two sectors are close substitutes. Assuming a high degree of substitutability biases the results against finding important aggregate effects of credit-market frictions in this setup; however, our results turned out to be not very sensitive to the choice of $\rho$. With sector-specific adjustment costs, the effective marginal cost of adjusting the aggregate capital stock is dramatically increased owing to the additional curvature implied by the two sector model. To achieve the same degree of overall capital adjustment as in the one-sector model we lower the adjustment cost elasticity $\varphi$ from 0.25 to 0.1 . Finally, we allow for a one-period delay in the investment of sector- 2 firms and a two period delay for sector-1 firms. This choice is based on the observation that credit-constrained firms tend to be smaller, and thus likely more flexible [see, e.g., Gertler and Gilchrist (1994)]. All other parameters are the same as in the baseline DNK model.

Figure 6 shows the results of a shock to monetary policy in the model with heterogeneous firms. The top left panel shows the response of output (the solid line),

\footnotetext{
29 Bernanke and Gertier $(1989,1990)$ argue that the financial accelerator mechanism provides a formal rationale for Fisher's debt-deflation theory of the Great Depression.
} 


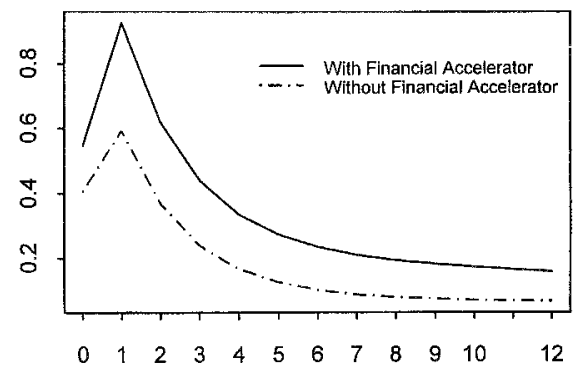

Output

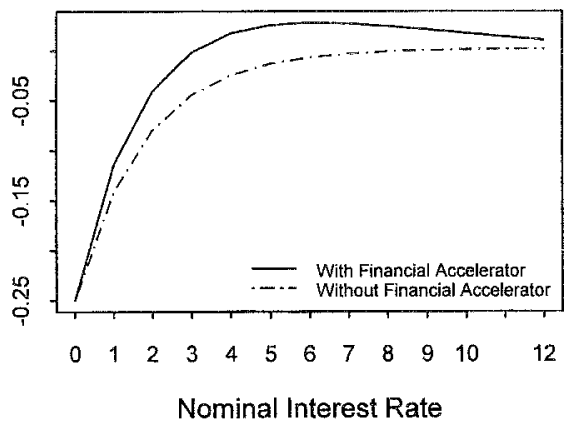

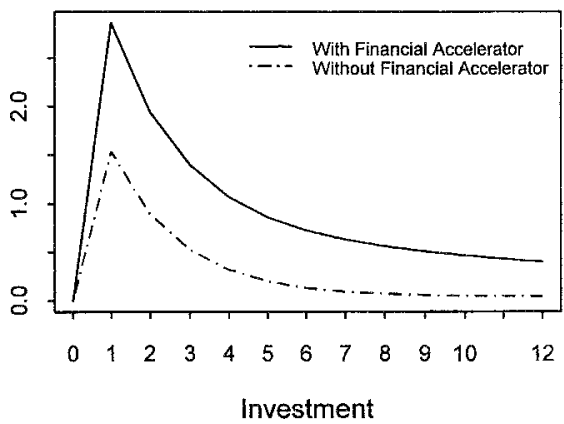

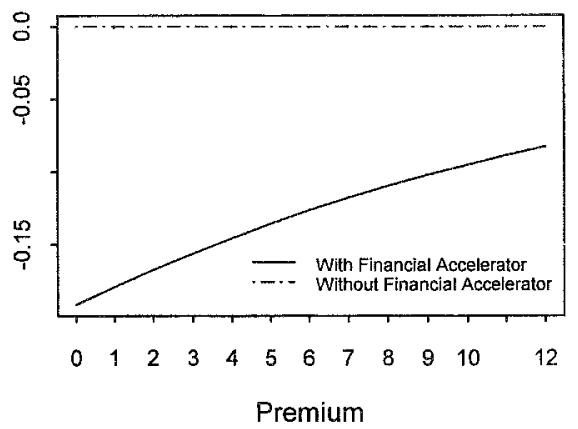

Fig. 5. Monetary shock - one period investment delay. All panels: time horizon in quarters.

relative to the baseline case with the financial accelerator shut off (the hatched line). In response to an unanticipated fall in the funds rate, output rises by approximately the same amount as it did in the aggregative New Keynesian model with investment delays, both for the baseline model without credit-market frictions and for the complete model with differential access of firms to credit. One interesting difference is that the differential investment delays across sectors smooth out the hump-shaped response of output, adding to the overall persistence of the output response. Thus, the effect of credit-market frictions on the propagation of shocks is roughly the same in the onesector and two-sector versions of the model.

The two-sector model also has cross-sectional implications, of course. The top and bottom panels on the right side of Figure 6 show the sectoral responses of output and investment. The solid line corresponds to the sector facing the relatively higher cost of external finance and the dotted line corresponds to the other sector. We find that, in response to an expansionary monetary policy shock, investment by firms with relatively poor access to external credit markets rises by nearly three times as much as the investment of firms with better access to credit. This "excess sensitivity" of the more constrained firms is consistent with evidence reported by Gertler and Gilchrist (1994), Kashyap, Lamont and Stein (1994), Oliner and Rudebusch (1994), Morgan (1998), and 


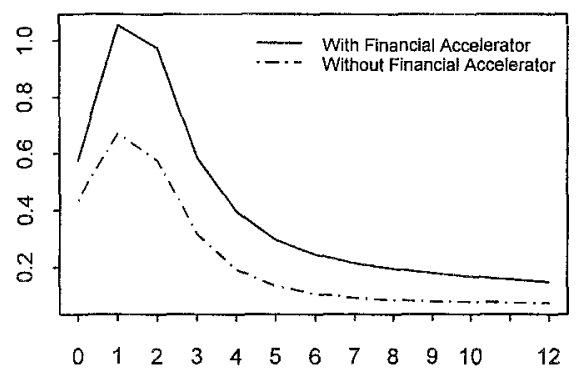

Aggregate Output

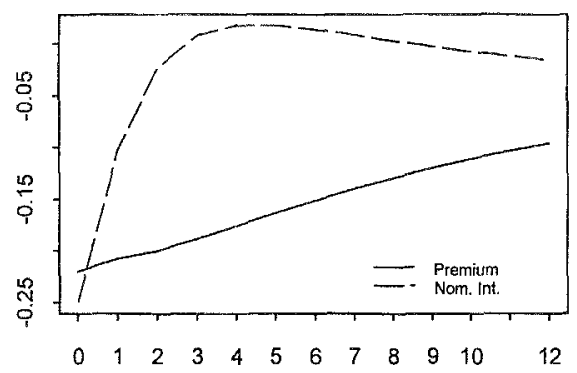

Premium and Nominal Interest Rate
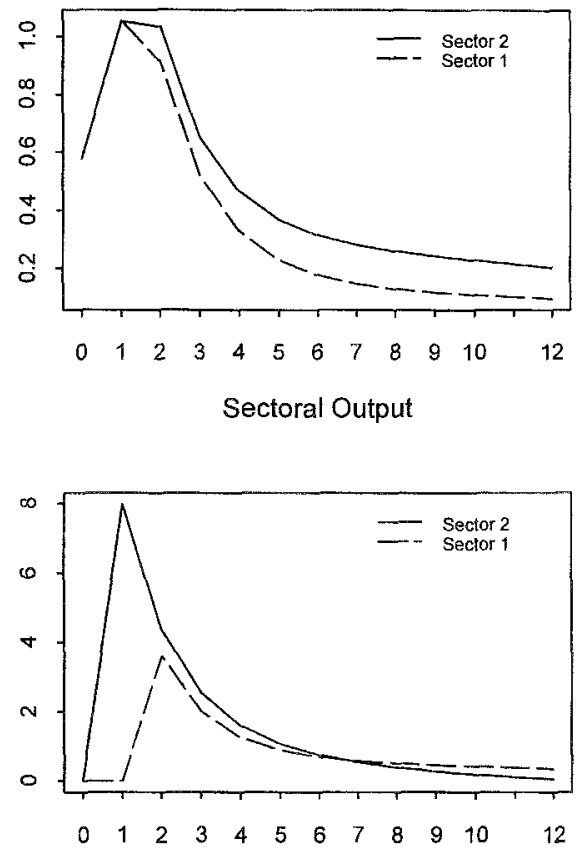

Sectoral Investment

Fig. 6. Monetary shock - multisector model with investment delays. All panels: time horizon in quarters. Aggregate output: models with and without financial accelerator; other panels: model with financial accelerator.

others. Although investment differs sharply across firms in the simulation, changes in output are similar for the two types of firms. Differing output effects could be produced, for example, by introducing inventories or inputs to production that must be financed by borrowing.

Our finding that constrained firms' investment spending reacts more strongly to monetary policy contrasts with that of Fisher (1996), who obtains an ambiguous result. We suspect that the main source of the difference in predictions is that, in our setting, borrowers' net worth is endogenous and is a key channel through which monetary policy affects credit availability. In Fisher's model, in contrast, borrowers' equity positions are exogenously fixed and are unaffected by changes in policy.

\section{A highly selected review of the literature}

The theoretical and empirical literatures on credit-market imperfections are immense. Until recently, the great bulk of this research has been partial equilibrium in nature, e.g., theoretical analyses of equilibria in credit markets with asymmetric information 
and agency costs, or empirical studies of the effects of credit-market imperfections on various types of spending, including consumption, housing, business investment, and inventory investment. Some leading recent examples of the latter category are cited in the introduction; see, e.g., Bernanke, Gertler and Gilchrist (1996) for additional references. Other surveys of these literatures which the reader may find useful include Gertler (1988), Gertler and Hubbard (1988), Jaffee and Stiglitz (1990), Bernanke (1993), Calomiris (1993), Gertler and Gilchrist (1993), Kashyap and Stein (1994), Oliner and Rudebusch (1994), Bernanke and Gertler (1995), and Hubbard (1995). To keep our survey of relevant literature brief, we limit consideration to the more recent work that, like the present research, studies the implications of credit-market frictions for macroeconomic dynamics. Even within this limited field our review must necessarily be selective; we focus on the work that bears the closest relationship to the model we have presented. In particular, we do not discuss the burgeoning related literature on the role of financial markets in economic growth [see, e.g., Levine (1997) for a survey of this topic] or in economic development [see, e.g., Townsend (1995)]. Nor do we consider research focusing on the role of banks in business cycles, primarily because there has been little work on the "bank lending channel" and related effects in an explicitly dynamic context ${ }^{30}$. We do believe however that the incorporation of a banking sector into our model would be a highly worthwhile exercise. Indeed, given that commercial banks borrow to order to fund investments in information-intensive, risky projects, and in this way bear resemblance to the entrepreneurs in our model, one could envision a relatively straightforward that allows for agency frictions int the intermediary sector.

On the theoretical side, the two principal antecedents of the approach used in the present chapter are Bernanke and Gertler (1989) and Kiyotaki and Moore (1997). Bernanke and Gertler (1989) analyze an overlapping-generations model in which borrowers/firms with fixed-size investment projects to finance face the "costly state verification" problem of Townsend (1979) and Gale and Hellwig (1985) ${ }^{31}$. As we discussed in detail in the presentation of our model above, the optimal contract in this setting has the features of a standard debt contract. As we noted earlier, the principal virtue of this setup, other than simplicity, is that it motivates an inverse relationship between the potential borrower's wealth and the expected agency costs of the lenderborrower relationship (here, the agency costs are equated with monitoring/bankruptcy costs). In particular, a potential borrower with high net worth needs to rely relatively little on external finance; he thus faces at most a small risk of bankruptcy and a small

\footnotetext{
${ }^{30}$ Interesting recent exceptions are Gersbach (1997) and Krishnamurthy (1997). Holmstrom and Tirole (1997) analyze the role of bank collateral and monitoring in a static context. Several papers have studied the role of banks in the context of "limited participation" models, see for example Fisher (1996) and Cooley and Quadrini (1997).]

31 Williamson (1987) also incorporates the costly state verification assumption into a modified real business cycle model.
} 
premium on external finance. A borrower with less resources of his own to invest, in contrast, faces a high bankruptcy risk and a high external finance premium.

In the Bernanke-Gertler model, shocks to the economy are amplified and propagated by their effects on borrowers' cash flows. For example, an adverse productivity shock lowers current cash flows, reducing the ability of firms to finance investment projects from retained earnings. This decline in net worth raises the average external finance premium and the cost of new investments. Declining investment lowers economic activity and cash flows in subsequent periods, amplifying and propagating the effects of the initial shock. Bernanke and Gertler show that this effect can generate serially correlated movements in aggregate output, even though the exogenous shocks to the system are i.i.d. They also show that in their model the dynamics of the cycle are nonlinear; in particular, the weaker the initial financial condition of borrowers, the more powerful is the propagation effect through cash flows. A number of subsequent papers have shown that this basic analysis can be extended and deepened without affecting the qualitative results: For example, Gertler (1992) considers the case of multi-period financial contracts. Aghion and Bolton (1997) give an extensive analysis of the shortrun and long-run dynamic behavior of a closely-related model. And Aghion, Banerjee and Piketty (1997) show how the dynamics of this sort of model are affected when interest rate movements are endogenous (Bernanke and Gertler assume that the real interest rate is fixed by the availability of an alternative technology.) The model that we presented utilizes a number of the features of the Bernanke-Gertler model, notably the overlapping-generations assumption for entrepreneurs and the costly state verification model of intermediation. As in Bernanke and Gertler (1989), our model here implies a central role for the endogenous evolution of borrowers' net worth in macroeconomic dynamics.

Other authors have developed dynamic macroeconomic models in which cash flows play a critical role in the propagation mechanism. Notably, Greenwald and Stiglitz (1993) construct a model in which, as in Bernanke and Gertler (1989), firms have access only to debt financing (equity finance is ruled out by assumption). Because bankruptcy is costly, firms are reluctant to become highly levered; their initial equity or net worth thus effectively constrains the quantity of funds that they can raise in capital markets. Greenwald and Stiglitz assume that there is a one-period lag between the use of variable inputs and the production of output. A firm that suffers a decline in cash flow is able to finance fewer inputs and less production. Lower production. implies lower profits, which propagates the effects of the initial fall in cash flow. The Greenwald-Stiglitz model thus illustrates that financial factors may affect the level of inputs, such as employment or inventories, as well as the level of capital investment (as in Bernanke-Gertler). The basic intuition concerning how credit-market imperfections propagate the cycle is similar in the two models, however.

The net worth of borrowers changes not only in response to variations in cash flow, but also (and often, more dramatically) to changes in the valuation of the real and financial assets that they hold. Indeed, changes in asset values are taken by Fisher (1933) and other classical writers on the subject to be the principal means by which 
financial forces propagate an economic decline. This element was added to the formal literature by Kiyotaki and Moore (1997), who develop a dynamic equilibrium model in which endogenous fluctuations in the market prices of an asset (land, in their example) are the main source of changes in borrowers' net worth and hence in spending and production $^{32}$.

Kiyotaki and Moore analyze a stylized example in which land serves both as a factor of production and as a source of collateral for loans to producers. In this economy, a temporary shock (to productivity, for example) lowers the value of land and hence of producers' collateral. This leads in turn to tightened borrowing constraints, less production and spending, and finally to still further reductions in land values, which propagates the shock further through time ${ }^{33}$. We consider the asset-price channel to be an important one, and it plays an important role in generating the significant quantitative effects we obtained in our calibration exercises ${ }^{34}$.

Turning from theoretical to empirical research, we note that there are very few examples of fully articulated macro models including capital-market imperfections that have been estimated by classical methods (the major exception being some large macroeconometric forecasting models, as noted in the introduction). The quantitative research most closely related to the present chapter uses the calibration technique. Our work here is particularly influenced by Carlstrom and Fuerst (1997), which in turn draws from analyses by Fisher (1996), Fuerst (1995) and Gertler (1995), as well as from the theoretical model of Bernanke and Gertler (1989) discussed above.

As we do in the model presented in this chapter, Carlstrom and Fuerst (1997) study the optimal lending contract between financial intermediaries and entrepreneurs when verifying the return to entrepreneurs' projects is costly for the lender. They then embed the resulting representation of credit markets in an otherwise conventional real business cycle model. They find that the endogenous evolution of net worth plays an important role in the simulated dynamic responses of the model to various types of shock.

\footnotetext{
32. Suarez and Sussman (1997) present a dynamic model in which asset price declines, induced by "fire sales" by bankrupt firms, contribute to cyclical fluctuations.

33 In the model we presented earlier, entrepreneurs do not obtain insurance against aggregate shocks because their indirect utility functions are linear in wealth (due to the assumptions of risk neutrality and constant returns to scale), while houscholds are risk-averse. Krishnamurthy (1997) points out that in more general settings entrepreneurs are likely to want to obtain this kind of insurance, which raises the question of why the posited credit-market effects should be empirically relevant. Krishnamurthy's answer is that the ability of lenders or other insurers to insure against large aggregate shocks depends in turn on the insurers' own net worth, which may be reduced during a severe recession. He goes on to develop a model with implications similar to that of Kiyotaki and Moore (1997), except that it is the net worth of lenders or insurers, rather than that of borrowers, that plays the crucial role. See Kiyotaki and Moore (1998) for a related argument.

34 Another potentially interesting channel, cmphasized by Kiyotaki and Moore (1998), involves the interdependency that arises from credit chains, where firms are simultancously lending and borrowing. These authors show that small shocks can induce a kind of domino effect, due to the chain, that leads to big effects on the economy.
} 
An interesting finding of their research is that the model with credit-market frictions generates a hump-shaped output response, consistent with most empirical findings. Our model presented above has many features in common with that of Carlstrom and Fuerst (1997). Putting aside some technical details, there are however two major differences between the two models. First, we consider a sticky-price setting in the Dynamic New Keynesian tradition, while Carlstrom and Fuerst restrict themselves to a model with flexible prices. Thus we are able to examine the interaction of credit-market frictions with shocks to monetary policy, or to other nominal variables. The second difference is more subtle but is also important: Carlstrom and Fuerst assume that the agency problem applies only to producers of investment goods, who produce capital directly from the output good. The output good is produced, using both capital and labor, by separate firms who do not face agency problems in external finance. As a result of these assumptions, in the Carlstrom-Fuerst model, changes in net worth affect the economy primarily by affecting the supply price of capital (when net worth is low, less capital is produced at any given price). In our model, in contrast, the agency problem applies to producers of final output, who own the economy's durable capital stock. Since borrowers own the economy's capital stock, changes in the price of capital directly affect their net worth; that is, our model more directly incorporates the asset price effects stressed by Kiyotaki and Moore (1997). As a result, we find that creditmarket frictions amplify shocks to the economy to a greater degree than do Carlstrom and Fuerst. On the other hand, a clear virtue of Carlstrom-Fuerst model is that the credit-mechanism helps able to explain the real world auto-correlation properties of output.

\section{Directions for future work}

In subsequent research we hope to consider several extensions to the work so far:

First, as noted above, we have not addressed the role of banks in cyclical fluctuations, despite considerable attention to banking in the previous theoretical and empirical literatures. There are several ways to incorporate a nontrivial role for banks into our framework; one possibility is to allow the financial intermediaries which lend to entrepreneurs to face financial frictions in raising funds themselves. In this case, the net worth of the banking sector, as well as the net worth of entrepreneurs, will matter for the models' dynamics.

Second, an important institutional fact is that debt contracts in low-inflation countries are almost always set in nominal terms, rather than in real terms as in this chapter. It would be relatively easy to incorporate nominal contracting into this model, in order to evaluate whether the redistributions among debtors and creditors associated with unanticipated changes in the price level are of quantitative significance. Doing so would enable us to critically assess recent arguments that deflation may pose a serious threat to the US economy. 
Third, we have restricted the analysis to a closed economy. It would be interesting to extend the analysis to the open economy. By doing so it would be possible to analyze how a currency crisis may induce financial distress that is transmitted to the real sector ${ }^{35}$. As we discussed in Section 5, to the extent an exchange rate collapse redistributes wealth from domestic borrowers to domestic lenders (owing to the fact that loans are denominated in units of foreign currency), the model of our chapter predicts a contraction in real activity.

Finally, in this chapter we have restricted the credit-market frictions to the investment sector. It would be interesting to study how the results might be affected if these frictions affect other components of spending, such as consumption, inventory investment, and housing.

\section{Appendix A. The optimal financial contract and the demand for capital}

In this appendix we provide a detailed analysis of the partial equilibrium costly-stateverification problem discussed in Section 3. We start with the case of no aggregate risk and show that under the assumptions made in the text, the optimal contract provides a monotonically increasing relationship between the capital/wealth ratio and the premium on external funds: $Q K / N=\psi\left(R^{K} / R\right)$ with $\psi^{\prime}(\cdot)>0$. We also establish that the default probability $\bar{\omega}$ is a strictly increasing function of the premium $R^{K} / R$, implying that the optimal contract guarantees an interior solution and therefore does not involve quantity rationing of credit. This appendix also provides functional forms for the contract structure. In particular, for the case of the log-normal distribution we provide exact analytical expressions for the payoff functions to the lender and entrepreneur. In the final section of this appendix we extend the analysis to the case of aggregate risk and show that the previously established results continue to hold.

\section{A.1. The partial equilibrium contracting problem}

Let profits per unit of capital equal $\omega R^{k}$, where $\omega \in[0, \infty)$ is an idiosyncratic shock with $E(\omega)=1$. We assume $F(x)=\operatorname{Pr}[\omega<x]$ is a continuous probability distribution with $F(0)=0$. We denote by $f(\omega)$ the pdf of $\omega$. Given an initial level of net worth $N$, and a price of capital $Q$, the entrepreneur borrows $Q K-N$, to invest $K$ units of capital in the project. The total return on capital is thus $\omega R^{k} Q K$. We assume $\omega$ is unknown to both the entrepreneur and the lender prior to the investment decision. After the investment decision is made, the lender can only observe $\omega$ by paying the monitoring $\operatorname{cost} \mu \omega R^{k} Q K$, where $0<\mu<1$. Let the required return on lending equal $R$, with $R<R^{K}$.

35 See Mishkin (1997) for a discussion of how the financial accelerator mechanisn may be useful for understanding the recent currency crises in Mexico and Southeast Asia. 
The optimal contract specifies a cutoff value $\bar{\omega}$ such that if $\omega \geqslant \bar{\omega}$, the borrower pays the lender the fixed amount $\bar{\omega} R^{K} Q K$ and keeps the equity $(\omega-\bar{\omega}) R^{K} Q K$. Alternatively, if $\omega<\bar{\omega}$, the borrower receives nothing, while the lender monitors the borrower and receives $(1-\mu) \omega R^{K} Q K$ in residual claims net of monitoring costs. In equilibrium, the lender earns an expected return equal to the safe rate $R$ implying

$$
[\bar{\omega} \operatorname{Pr}(\omega \geqslant \bar{\omega})+(1-\mu) E(\omega \mid \omega<\bar{\omega}) \operatorname{Pr}(\omega<\bar{\omega})] R^{K} Q K=R(Q K-N) .
$$

Given constant returns to scale, the cutoff $\bar{\omega}$ determines the division of expected gross profits $R^{K} Q K$ between borrower and lender. We define $\Gamma(\bar{\omega})$ as the expected gross share of profits going to the lender:

$$
\Gamma(\omega) \equiv \int_{0}^{\bar{\omega}} \omega f(\omega) \mathrm{d} \omega+\bar{\omega} \int_{\bar{\omega}}^{\infty} f(\omega) \mathrm{d} \omega,
$$

and note that

$$
\Gamma^{\prime}(\bar{\omega})=1-F(\bar{\omega}), \quad \Gamma^{\prime \prime}(\bar{\omega})=-f(\bar{\omega})
$$

implying that the gross payment to the lender is strictly concave in the cutoff value $\bar{\omega}$. We similarly define $\mu G(\bar{\omega})$ as the expected monitoring costs:

$$
\mu G(\bar{\omega}) \equiv \mu \int_{0}^{\bar{\omega}} \omega f(\omega) \mathrm{d} \omega
$$

and note that

$$
\mu G^{\prime}(\bar{\omega}) \equiv \mu \bar{\omega} f(\bar{\omega})
$$

The net share of profits going to the lender is $\Gamma(\bar{\omega})-\mu G(\bar{\omega})$, and the share going to the entrepreneur is $1-\Gamma(\bar{\omega})$, where by definition $\Gamma(\bar{\omega})$ satisfies $0<\Gamma(\bar{\omega})<1$.

The assumptions made above imply:

$$
\Gamma(\bar{\omega})-\mu G(\bar{\omega})>0 \text { for } \bar{\omega} \in(0, \infty)
$$

and

$$
\lim _{\bar{\omega} \rightarrow 0} \Gamma(\bar{\omega})-\mu G(\bar{\omega})=0, \quad \lim _{\bar{\omega} \rightarrow \infty} \Gamma(\bar{\omega})-\mu G(\bar{\omega})=1-\mu
$$

We therefore assume that $R^{k}(1-\mu)<R$, otherwise the firm could obtain unbounded profits under monitoring that occurs with probability one ${ }^{36}$.

\footnotetext{
36 The bound on $\Gamma(\bar{\omega})$ can be easily seen from the fact that both $\Gamma(\bar{\omega})-E(\omega \mid \omega<\bar{\omega}) \operatorname{Pr}(\omega<\bar{\omega})+$ $\bar{\omega} \operatorname{Pr}(\omega \geqslant \bar{\omega})$ and $1-\Gamma(\bar{\omega})=(E(\omega \mid \omega \geqslant \bar{\omega})-\bar{\omega}) \operatorname{Pr}(\omega \geqslant \bar{\omega})$ are positive. The limits on $\Gamma(\bar{\omega})-\mu G(\bar{\omega})$ can be seen by recognizing that $G(\bar{\omega})=E(\omega \mid \omega<\bar{\omega}) \operatorname{Pr}(\omega<\bar{\omega})$ so that $\lim _{\bar{\omega} \rightarrow \infty} G(\bar{\omega})=E(\omega)=1$.
} 
Let $h(\bar{\omega}) \equiv(f(\bar{\omega}) /(1-F(\bar{\omega}))$, the hazard rate. We assume that $\bar{\omega} h(\bar{\omega})$ is increasing in $\bar{\omega}^{37}$. There are two immediate implications from this assumption regarding the shape of the net payoff to the lender. First, differentiating $\Gamma(\bar{\omega})-\mu G(\bar{\omega})$, there exists an $\bar{\omega}^{*}$ such that

$$
\Gamma^{\prime}(\bar{\omega})-\mu G^{\prime}(\bar{\omega})=(1-F(\bar{\omega}))(1-\mu \bar{\omega} h(\bar{\omega})) \lesseqgtr 0 \quad \text { for } \quad \bar{\omega} \gtreqless \bar{\omega}^{*},
$$

implying that the net payoff to the lender reaches a global maximum at $\bar{\omega}^{*}$.

The second implication of this assumption is that

$$
\Gamma^{\prime}(\bar{\omega}) G^{\prime \prime}(\omega)-\Gamma^{\prime \prime}(\omega) G^{\prime}(\omega)=\frac{\mathrm{d}(\bar{\omega} h(\bar{\omega}))}{\mathrm{d} \bar{\omega}}(1-F(\bar{\omega}))^{2}>0 \quad \text { for all } \bar{\omega}
$$

These two implications are used to guarantee a non-rationing outcome.

The optimal contracting problem with non-stochastic monitoring may now be written as

$$
\begin{aligned}
& \max _{K, \bar{\omega}}(1-\Gamma(\bar{\omega})) R^{k} Q K \\
& \quad \text { subject to }[\Gamma(\bar{\omega})-\mu G(\bar{\omega})] R^{k} Q K=R(Q K-N) .
\end{aligned}
$$

It is easiest to analyse this problem by first explicitly defining the premium on external funds $s=R^{k} / R$ and then, owing to constant returns to scale, normalizing by wealth and using $k=Q K / N$ the capital/wealth ratio as the choice variable ${ }^{38}$. Defining $\lambda$ as the Lagrange multiplier on the constraint that lenders earn their required rate of return

37 Any monotonically increasing transformation of the normal distribution satisfies this condition. To see this, define the inverse transformation $z=z(\bar{\omega}), z^{\prime}(\bar{\omega})>0$, with $z \sim N(0,1)$. The hazard rate for the standard normal satisfies $h(z)=\phi(z) /(1-\Phi(z))$, implying

$$
\bar{\omega} h(\bar{\omega})=\frac{\bar{\omega} \phi(z(\bar{\omega}))}{(1-\Phi(z(\bar{\omega})))}
$$

Differentiating $\bar{\omega} h(\bar{\omega})$ we obtain

$$
\frac{\mathrm{d}(\bar{\omega} h(\bar{\omega}))}{\mathrm{d} \bar{\omega}}=h(z(\bar{\omega}))+\bar{\omega} h^{\prime}(z(\bar{\omega})) z^{\prime}(\bar{\omega})>0
$$

where the inequality follows from the fact that the hazard rate for the standard normal is positive and strictly increasing.

${ }^{38}$ It is worth noting that the basic contract structure as well as the non-rationing outcome extends in a straightforward manner to the case of non-constant returns to capital, as long as monitoring costs remain proportional to capital returns. 
in expectation, the first-order conditions for an interior solution to this problem may be written:

$$
\begin{aligned}
\bar{\omega} & : \Gamma^{\prime}(\omega)-\lambda\left[\Gamma^{\prime}(\bar{\omega})-\mu G^{\prime}(\bar{\omega})\right]=0, \\
k & :[(1-\Gamma(\bar{\omega}))+\lambda(\Gamma(\bar{\omega})-\mu G(\bar{\omega})] s-\lambda=0, \\
\lambda & :[\Gamma(\bar{\omega})-\mu G(\bar{\omega})] s k-(k-1)=0 .
\end{aligned}
$$

Since $\Gamma(\bar{\omega})-\mu G(\bar{\omega})$ is increasing on $\left(0, \bar{\omega}^{*}\right)$ and decreasing on $\left(\bar{\omega}^{*}, \infty\right)$, the lender would never choose $\bar{\omega}>\bar{\omega}^{*}$. We first consider the case $0<\bar{\omega}<\bar{\omega}^{*}$ which implies an interior solution ${ }^{39}$. As we will show below, a sufficient condition to guarantee an interior solution is

$$
s<\frac{1}{\Gamma\left(\omega^{*}\right)-\mu G\left(\bar{\omega}^{*}\right)} \equiv s^{*} .
$$

We will argue below that $s \geqslant s^{*}$ cannot be an equilibrium.

Assuming an interior solution, the F.O.C. with respect to the cutoff $\bar{\omega}$ implies we can write the Lagrange multiplier $\lambda$ as a function of $\bar{\omega}$ :

$$
\lambda(\bar{\omega})=\frac{\Gamma^{\prime}(\bar{\omega})}{\Gamma^{\prime}(\bar{\omega})-\mu G^{\prime}(\bar{\omega})} .
$$

Taking derivatives we obtain

$$
\lambda^{\prime}(\bar{\omega})=\frac{\mu\left[\Gamma^{\prime}(\omega) G^{\prime \prime}(\bar{\omega})-\Gamma^{\prime \prime}(\bar{\omega}) G^{\prime}(\omega)\right]}{\left[\Gamma^{\prime}(\bar{\omega})-\mu G^{\prime}(\bar{\omega})\right]^{2}}>0 \text { for } \bar{\omega} \in\left(0, \bar{\omega}^{*}\right),
$$

where the inequality follows directly from the assumption that $\bar{\omega} h(\bar{\omega})$ is increasing. Taking limits we obtain

$$
\lim _{\bar{\omega} \rightarrow 0} \lambda(\bar{\omega})=1, \quad \lim _{\bar{\omega} \rightarrow \bar{\omega}^{*}} \lambda(\bar{\omega})=+\infty .
$$

Now define

$$
\rho(\bar{\omega}) \equiv \frac{\lambda(\bar{\omega})}{(1-\Gamma(\bar{\omega})+\lambda(\Gamma(\bar{\omega})-\mu G(\bar{\omega}))}
$$

then the F.O.C. imply that the cutoff $\bar{\omega}$ satisfies

$$
s=\rho(\bar{\omega})
$$

so that $\rho(\bar{\omega})$ is the wedge between the expected rate of return on capital and the safe return demanded by lenders. Again, computing derivatives we obtain

$$
\rho^{\prime}(\bar{\omega})=\rho(\bar{\omega}) \frac{\lambda^{\prime}(\bar{\omega})}{\lambda(\bar{\omega})}\left(\frac{1-\Gamma(\bar{\omega})}{1-\Gamma(\bar{\omega})+\lambda(\Gamma(\bar{\omega})-\mu G(\bar{\omega})}\right)>0 \text { for } \bar{\omega} \in\left(0, \bar{\omega}^{*}\right)
$$

and taking limits:

$$
\lim _{\bar{\omega} \rightarrow 0} \rho(\bar{\omega})=1, \quad \lim _{\bar{\omega} \rightarrow \bar{\omega}^{*}} \rho(\bar{\omega})=\frac{1}{\left(\Gamma\left(\bar{\omega}^{*}\right)-\mu G\left(\bar{\omega}^{*}\right)\right)} \equiv s^{*}<\frac{1}{1-\mu} .
$$

Thus, for $s<s^{*}$, these conditions guarantee a one-to-one mapping between the optimal cutoff $\bar{\omega}$ and the premium on external funds $s$. By inverting Equation (A.1) we may

${ }^{39}$ Obviously, $\omega=0$ cannot be a solution if $s>1$. 
express this relationship as $\bar{\omega}=\bar{\omega}(s)$, where $\bar{\omega}^{\prime}(s)>0$ for $s \in\left(1, s^{*}\right)$. Equation (A.1) thus establishes the monotonically increasing relationship between default probabilities and the premium on external funds.

Now define

$$
\Psi(\bar{\omega}) \equiv 1+\frac{\lambda(\Gamma(\bar{\omega})-\mu G(\bar{\omega}))}{1-\Gamma(\bar{\omega})}
$$

Then, given a cutoff $\bar{\omega} \in\left(0, \bar{\omega}^{*}\right)$ the F.O.C. imply a unique capital/wealth (and hence leverage) ratio:

$$
k=\Psi(\bar{\omega}) \text {. }
$$

Computing derivatives we obtain

$$
\Psi^{\prime}(\bar{\omega})=\frac{\lambda^{\prime}(\bar{\omega})}{\lambda(\bar{\omega})}(\Psi(\bar{\omega})-1)+\frac{\Gamma^{\prime}(\bar{\omega})}{1-\Gamma(\bar{\omega})} \Psi(\bar{\omega})>0 \quad \text { for } \quad \bar{\omega} \in\left(0, \bar{\omega}^{*}\right),
$$

and taking limits:

$$
\lim _{\bar{\omega} \rightarrow 0} \Psi(\bar{\omega})=1, \quad \lim _{\bar{\omega} \rightarrow \bar{\omega}^{*}} \Psi(\bar{\omega})=+\infty
$$

Combining Equation (A.1) with Equation (A.2) we may express the capital/wealth ratio as an increasing function of the premium on external funds:

$$
k=\psi(s)
$$

with

$$
\psi^{\prime}(s)>0 \text { for } s \in\left(1, s^{*}\right)
$$

Since $\lim _{\bar{\omega} \rightarrow \bar{\omega}^{*}} \Psi(\bar{\omega})=+\infty$ and $\lim _{\bar{\omega} \rightarrow \omega^{*}} \rho(\bar{\omega})=s^{*}$, as $s$ approaches $s^{*}$ from below, the capital stock becomes unbounded. In equilibrium this will lower the excess return $s$.

Now consider the possibility that the lender sets $\bar{\omega}=\bar{\omega}^{*}$. The lender would only do so if the excess return $s$ is greater than $s^{*}$. In this case, the lender receives an expected excess return equal to

$$
\left(\Gamma\left(\bar{\omega}^{*}\right)-\mu G\left(\bar{\omega}^{*}\right)\right) s k-k=\frac{s-s^{*}}{s^{*}} k>0 .
$$

Since the expected excess return is strictly positive for all $k$, the lender is willing to lend out an arbitrary large amount, and both the borrower and lender can obtain unbounded profits. Again, such actions would drive down the rate of return on capital 
in equilibrium, ensuring $s<s^{*}$ and guaranteeing an interior solution for the cutoff $\bar{\omega} \in\left(0, \bar{\omega}^{*}\right)$.

\section{A.2. The log-normal distribution}

In this section, we provide analytical expressions for $\Gamma(\bar{\omega})$ and $\Gamma(\bar{\omega})-\mu G(\bar{\omega})$, for the case where $\omega$ is distributed log-normally ${ }^{40}$. Under the assumption that $\ln (\omega) \sim N\left(-\frac{1}{2} \sigma^{2}, \sigma^{2}\right)$ we have $E(\omega)=1$ and

$$
E(\omega \mid \omega \geqslant \bar{\omega})=\frac{1-\Phi(z-\sigma)}{1-\Phi(z)},
$$

where $\Phi(\cdot)$ is the c.d.f. of the standard normal and $z$ is related to $\bar{\omega}$ through $z \equiv\left(\ln (\bar{\omega})+0.5 \sigma^{2}\right) / \sigma$. Using the fact that $1-\Gamma(\bar{\omega})=(E(\omega \mid \omega \geqslant \bar{\omega})-\bar{\omega}) \operatorname{Pr}(\omega \geqslant \bar{\omega})$, we obtain

$$
\Gamma(\bar{\omega})=\Phi(z-\sigma)+\bar{\omega}[1-\Phi(z)]
$$

and

$$
\Gamma(\bar{\omega})-\mu G(\bar{\omega})=(1-\mu) \Phi(z-\sigma)+\bar{\omega}[1-\Phi(z)]
$$

\section{A.3. Aggregate risk}

To accommodate the possibility of aggregate risk, we modify the contracting framework in the following manner. Let profits per unit of capital expenditures now equal $\tilde{u} \omega R^{k}$ where $\omega$ represents the idiosyncratic shock, $\tilde{u}$ represents an aggregate shock to the profit rate, and $E(\omega)=E(\tilde{u})=1$. Since entrepreneurs are risk neutral, we assume that they bear all the aggregate risk associated with the contract. Again, letting $s=\frac{R^{k}}{R}$ the ex ante premium on external funds, and $k=Q K / N$, capital per dollar of self-financing, the optimal contracting problem may be now be written:

$$
\max _{k, \bar{\omega}} E\{(1-\Gamma(\bar{\omega})) \tilde{u} s k+\lambda[(\Gamma(\bar{\omega}) \cdots \mu G(\bar{\omega})) \tilde{u} s k-(k-1)]\}
$$

where $\lambda$ is the ex post value (after the realization of the aggregate shock $\tilde{u}$ ) of the Lagrange multiplier on the constraint that lenders earn their required return and $E\{\}$ refers to expectations taken over the distribution of the aggregate shock $\tilde{u}$.

We wish to establish that with the addition of aggregate risk, the capital/wealth ratio $k$ is a still an increasing function of the ex ante premium on external funds. Define

40 Since the log-normal is a monotonic transformation of the normal, it satisfies the condition $\mathrm{d}(\bar{\omega} h(\bar{\alpha})) / \mathrm{d} \bar{\omega}>0$. 
$\gamma(\bar{\omega}) \equiv 1-\Gamma(\bar{\omega})+\lambda(\Gamma(\bar{\omega})-\mu G(\bar{\omega}))$. The first-order conditions for the contracting problem may be written as

$$
\begin{aligned}
& \bar{\omega}: \Gamma^{\prime}(\bar{\omega})-\lambda\left[\Gamma^{\prime}(\bar{\omega})-\mu G^{\prime}(\bar{\omega})\right]=0, \\
& k: E\{Y(\bar{\omega}) \tilde{u} s-\lambda(\bar{\omega})\}=0, \\
& \lambda:(\Gamma(\bar{\omega})-\mu G(\bar{\omega})) \tilde{u} s-(k-1)=0 .
\end{aligned}
$$

Again, under no rationing, the first-order condition with respect to $\bar{\omega}$ defines the function $\lambda(\bar{\omega})$. This function is identical to $\lambda(\bar{\omega})$ defined in the case of no aggregate risk. The constraint that lenders earn their required rate of return defines an implicit function for the cutoff $\bar{\omega}=\bar{\omega}(\tilde{u}, s, k)^{41}$. Computing derivatives we obtain

$$
\frac{\partial \bar{\omega}}{\partial s}=\frac{-(\Gamma(\bar{\omega})-\mu G(\bar{\omega}))}{\left.\left(\Gamma^{\prime}(\bar{\omega})-\mu G^{\prime}(\overline{(})\right)\right) s}<0
$$

and

$$
\frac{\partial \bar{\omega}}{\partial k}=\frac{1}{\left(\Gamma^{\prime}(\bar{\omega})-\mu G^{\prime}(\bar{\omega})\right)(\tilde{u} s)}>0 .
$$

To obtain a relationship of the form $k=\psi(s), \psi^{\prime}(s)>0$ we totally differentiate the first-order condition with respect to capital:

$$
E\left\{\tilde{u} \gamma^{\prime}(\bar{\omega}) d s+\tilde{u} s \gamma^{\prime \prime}(\bar{\omega})\left(\frac{\partial \bar{\omega}}{\partial s} d s+\frac{\partial \bar{\omega}}{\partial k} d k\right)-\lambda^{\prime}(\bar{\omega})\left(\frac{\partial \bar{\omega}}{\partial s} d s+\frac{\partial \bar{\omega}}{\partial k} d k\right)\right\}=0
$$

Rearranging gives

$$
\frac{d k}{d s}=\frac{E\left\{\left(\tilde{u} s \Upsilon^{\prime}(\bar{\omega})-\lambda^{\prime}(\bar{\omega})\right) \frac{\partial \bar{\omega}}{\partial s}+\tilde{u} \gamma^{\prime}(\bar{\omega})\right\}}{E\left\{\left(\lambda^{\prime}(\bar{\omega})-\tilde{u} s \Upsilon^{\prime}(\bar{\omega})\right) \frac{\partial \bar{\omega}}{\partial k}\right\}}
$$

Using the fact that

$$
r^{\prime}(\bar{\omega})=\lambda^{\prime}(\bar{\omega})(\Gamma(\bar{\omega})-\mu G(\bar{\omega}))
$$

41 As a technical matter, it is possible that the innovation in aggregate returns is sufficiently low that $\bar{\omega}(\mu, s, k)>\bar{\omega}^{*}$, in which case the lender would set $\bar{\omega}=\bar{\omega}^{*}$ and effectively absorb some of the aggregate risk. We rule out this possibility by assumption. An alternative interpretation is that we solve a contracting problem that is approximately correct and note that in our parametrized model aggregate shocks would have to be implausibly large before such distortions to the contract could be considered numerically relevant. 
we obtain

$$
\begin{aligned}
\lambda^{\prime}(\bar{\omega})-\gamma^{\prime}(\bar{\omega}) \tilde{u} s & =\lambda^{\prime}(\bar{\omega})[1-(\Gamma(\bar{\omega})-\mu G(\bar{\omega})) \tilde{u} s] \\
& =\lambda^{\prime}(\bar{\omega}) k^{-1}
\end{aligned}
$$

implying that $d k / d s$ simplifies to the expression

$$
\frac{d k}{d s}=\frac{E\left\{\tilde{u} s \Upsilon(\bar{\omega})-\lambda^{\prime}(\bar{\omega}) \frac{\partial \bar{\omega}}{\partial s}\right\}}{E\left\{\lambda^{\prime}(\bar{\omega}) \frac{\partial \bar{\omega}}{\partial k}\right\}} .
$$

Since $\partial \bar{\omega} / \partial s<0, \partial \bar{\omega} / \partial k>0$, and $\lambda^{\prime}(\bar{\omega})>0$, the numerator and denominator of this expression are positive, thus establishing the positive relationship between the capital/wealth ratio $k$ and the premium on external funds $s$.

\section{Appendix B. Household, retail and government sectors}

We now describe the details of the household, retail, and government sectors that, along with details of the entrepreneurial sector presented in Section 4, underlie the log-linearized macroeconomic framework.

\section{B.1. Households}

Our household sector is reasonably conventional. There is a continuum of households of length unity. Each household works, consumes, holds money, and invests its savings in a financial intermediary that pays the riskless rate of return. $C_{t}$ is household consumption, $M_{t} / P_{t}$ is real money balances acquired at $t$ and carried into $t+1$, $H_{t}$ is household labor supply, $W_{t}$ is the real wage for household labor, $T_{t}$ is lump sum taxes, $D_{t}$ is deposits held at intermediaries (in real terms), and $\Pi_{t}$ is dividends received from ownership of retail firms. The household's objective is given by

$$
\max E_{t} \sum_{k=0}^{\infty} \beta^{k}\left[\ln \left(C_{t+k}\right)+\zeta \ln \left(M_{t+k} / P_{t+k}\right)+\xi \ln \left(1-H_{t+k}\right)\right]
$$

The individual household budget constraint is given by

$$
C_{t}=W_{t} H_{t}-T_{t}+\Pi_{t}+R_{t} D_{t}-D_{t+1}+\frac{\left(M_{t-1}-M_{t}\right)}{P_{t}}
$$

The household chooses $C_{t}, D_{t+1}, H_{t}$ and $M_{t} / P_{t}$ to maximize Equation (B.1) subject to Equation (B.2). Solving the household's problem yields standard first-order conditions for consumption/saving, labor supply, and money holdings:

$$
\frac{1}{C_{t}}=E_{t}\left\{\beta \frac{1}{C_{t+1}}\right\} R_{t+1}
$$




$$
\begin{aligned}
& W_{t} \frac{1}{C_{t}}=\xi \frac{1}{1-H_{t}}, \\
& \frac{M_{t}}{P_{t}}=\zeta C_{t}\left(\frac{R_{t+1}^{n}-1}{R_{t+1}^{n}}\right)^{-1},
\end{aligned}
$$

where $R_{t+1}^{n}$ is the gross nominal interest, i.e.,

$$
i_{t+1} \equiv R_{t+1}^{n} \frac{P_{t+1}}{P_{t}}-1
$$

Note that the first-order condition for $M_{t} / P_{t}$ implies that the demand for real money balances is positively related to consumption and inversely related to the net nominal interest rate.

Finally, note that in equilibrium, household deposits at intermediaries equal total loanable funds supplied to entrepreneurs:

$$
D_{t}=B_{t}
$$

\section{B.2. The retail sector and price setting}

As is standard in the literature, to motivate sticky prices we modify the model to allow for monopolistic competition and (implicit) costs of adjusting nominal prices. As is discussed in the text, we assume that the monopolistic competition occurs at the "retail" level.

Let $Y_{t}(z)$ be the quantity of output sold by retailer $z$, measured in units of wholesale goods, and let $P_{t}(z)$ be the nominal price. Total final usable goods, $Y_{t}^{f}$, are the following composite of individual retail goods:

$$
Y_{t}^{f}=\left[\int_{0}^{1} Y_{t}(z)^{(\epsilon-1) / \epsilon} \mathrm{d} z\right]^{\epsilon /(\epsilon-1)}
$$

with $\epsilon>1$. The corresponding price index is given by

$$
P_{t}=\left[\int_{0}^{1} P_{t}(z)^{(1-\epsilon)} \mathrm{d} z\right]^{1 /(1-\epsilon)} .
$$

Final output may then be either transformed into a single type of consumption good, invested, consumed by the government or used up in monitoring costs. In particular, the economy-wide resource constraint is given by

$$
Y_{t}^{\prime}=C_{t}+C_{t}^{e}+I_{t}+G_{t}+\mu \int_{0}^{\bar{\omega}_{t}} \omega \mathrm{d} F(\omega) R_{t}^{k} Q_{t-1} K_{t}
$$

where $C_{t}^{e}$ is entrepreneurial consumption and $\mu \int_{0}^{\omega_{t}} \omega \mathrm{d} F(\omega) R_{t}^{k} Q_{t-1} K_{t}$ reflects aggregate monitoring costs. 
Given the index (B.6) that aggregates individual retail goods into final goods, the demand curve facing each retailer is given by

$$
Y_{t}(z)=\left(\frac{P_{t}(z)}{P_{t}}\right)^{-\epsilon} Y_{t}^{f}
$$

The retailer then chooses the sale price $P_{t}(z)$, taking as given the demand curve and the price of wholesale goods, $P_{t}^{w}$.

To introduce price inertia, we assume that the retailer is free to change its price in a given period only with probability $1-\theta$, following Calvo (1983). Let $P_{t}^{*}$ denote the price set by retailers who are able to change prices at $t$, and let $Y_{t}^{*}(z)$ denote the demand given this price. Retailer $z$ chooses his price to maximize expected discounted profits, given by

$$
\sum_{k=0}^{\infty} \theta^{k} E_{t-1}\left[\Lambda_{i, k} \frac{P_{i}^{*}-P_{t+k}^{w}}{P_{t+k}} Y_{t+k}^{*}(z)\right]
$$

where the discount rate $\Lambda_{t, k} \equiv \beta C_{t} /\left(C_{t+k}\right)$ is the household (i.e., shareholder) intertemporal marginal rate of substitution, which the retailer takes as given, and where $P_{t}^{w} \equiv P_{t} / X_{t}$ is the nominal price of wholesale goods.

Differentiating the objective with respect to $P_{t}^{*}$ implies that the optimally set price satisfies

$$
\sum_{k=0}^{\infty} \theta^{k} E_{t-1}\left\{\Lambda_{t, k}\left(\frac{P_{t}^{*}}{P_{t+k}}\right)^{-c} Y_{t+\bar{k}}^{*}(z)\left[\frac{P_{t}^{*}}{P_{t+k}}-\left(\frac{\epsilon}{\epsilon-1}\right) \frac{P_{t+k}^{w}}{P_{t+k}}\right]\right\}=0 .
$$

Roughly speaking, the retailer sets his price so that in expectation discounted marginal revenue equals discounted marginal cost, given the constraint that the nominal price is fixed in period $k$ with probability $\theta^{k}$. Given that the fraction $\theta$ of retailers do not change their price in period $t$, the aggregate price evolves according to

$$
P_{t}=\left[\theta P_{l-1}^{1-\epsilon}+(1-\theta)\left(P_{t}^{*}\right)^{(1-\epsilon)}\right]^{1 /(1-\epsilon)},
$$

where $P_{t}^{*}$ satisfies Equation (B.11). By combining Equations (B.11) and (B.12), and then log-linearizing, it is possible to obtain the Phillips curve in the text, Equation (4.22).

\section{B.3. Government sector}

We now close the model by specifying the government budget constraint. We assume that government expenditures are financed by lump-sum taxes and money creation as follows:

$$
G_{t}=\frac{M_{t}-M_{i-1}}{P_{t}}+T_{t}
$$

The government adjusts the mix of financing between money creation and lump-sum taxes to support the interest rate rule given by Equation (4.25). 
This, in conjunction with the characterization in Section 5 of the entrepreneurial sector and the monetary policy rule and shock processes, completes the description of the model.

\section{References}

Aghion, P., and P. Bolton (1997), "A theory of trickle-down growth and development with debt overhang", Review of Economic Studies 64:151-172,

Aghion, P., A. Banerjee and T. Piketty (1997), "Dualism and macroeconomic volatility", unpublished paper (University College, MIT, and CEPREMAP, November).

Akerlof, G. (1970), "The market for lemons: quality uncertainty and the market mechanism", Quarterly Journal of Economics 85:488-500.

Bacchetta, P., and S. Gerlach (1997), "Consumption and credit constraints: some international evidence", Journal of Monetary Economics 40:207-238.

Bernanke, B.S. (1983), "Nonmonetary effects of the financial crisis in the propagation of the great depression", American Economic Review 73:257-276.

Bernanke, B.S. (1993), "Credit in the macroeconomy", Quarterly Review, Federal Reserve Bank of New York 18:50-70.

Bernanke, B.S., and M. Gertler (1989), "Agency costs, net worth, and business fluctuations", American Economic Review 79:14 -31.

Bernanke, B.S., and M. Gertler (1990), "Financial fragility and economic performance", Quarterly Journal of Economics 105:87-114.

Bernanke, B.S., and M. Gertler (1995), "Inside the black box: the credit channel of monetary policy transmission", Journal of Economic Perspectives 9:27-48.

Bernanke, B.S., and C. Lown (1992), "The credit crunch", Brookings Papers on Economic Activity $1992(2): 205-239$.

Bernanke, B.S., and I. Mihov (1998), "Measuring monetary policy", Quarterly Journal of Economics $113: 869-902$

Bernanke, B.S., and M. Woodford (1997), "Inflation targets and monetary policy", Journal of Money, Credit and Banking 29:653-684.

Bernanke, B.S., M. Gertler and S. Gilchrist (1996), "The financial accelerator and the flight to quality", Revicw of Economics and Statistics 78:1--15.

Blinder, A.S., and L.J. Maccini (1991), "Taking stock: a critical assessment of recent research on inventories", Journal of Economic Perspectives 5:73-96.

Brayton, F, A. Levin, R. Tryon and J.C. Williams (1997), "The evolution of macro models at the Federal Reserve Board", Board of Governors, Finance and Economics Discussion Series No. 29, May 1997.

Calomiris, C.W. (1993), "Financial factors in the Great Depression", Journal of Economic Perspectives 7:61-86

Calvo, G.A. (1983), "Staggered prices in a utility-maximizing framework", Journal of Monetary Economics 12:383-398.

Cantor, R. (1990), "Effects of leverage on corporate investment and hiring decisions", Quarterly Review, Federal Reserve Bank of New York 15:31-41.

Carlstrom, C., and T. Fuerst (1997), "Agency costs, net worth, and business fluctuations: a computable general equilibrium analysis", American Economic Review 87:893-910.

Carpenter, R.E., S.M. Fazzari and B.C. Petersen (1994), "Inventory (dis)investment, internal finance fluctuations and the business cycle", Brookings Papers on Economic Activity 1994(2):75-138.

Carroll, C.D. (1997), "Buffer-stock saving and the life cycle/permanent income hypothesis", Quarterly Journal of Economics 112:1-55. 
Chari, V.V., P.J. Kehoe and E.R. McGrattan (1996), "Sticky price models of the business cycle: can the contract multiplier solve the persistence problem?", Staff Report 217 (Federal Reserve Bank of Minneapolis).

Chirinko, R.S. (1993), "Business fixed investment spending: a critical survey of modelling strategies, empirical results, and policy implications", Journal of Economic Literature 31:1875-1911.

Christiano, L.J., and R. Todd (1996), "Time to plan and aggregate fluctuations", Federal Reserve Bank of Minneapolis Quarterly Review, Winter, 14-27.

Christiano, L.J., M. Eichenbaum and C.L. Evans (1996), "The effects of monetary policy shocks: evidence from the flow of funds", Review of Economics and Statistics 78:16-34.

Clarida, R., J. Gali and M. Gertler (1997), "Monetary policy rules and macreconomic stability: evidence and some theory", unpublished paper (New York University, March).

Cooley, T.F., and V. Quadrini (1997), "Monetary policy and the financial decisions of firms", unpublished paper (University of Rochester, December).

Cummins, J.G., K.A. Hassett and R.G. Hubbard (1994), "A reconsideration of investment behavior using tax reforms as natural expcriments", Brookings Papers on Economic Activity 1994(2):1-74.

Deaton, A. (1991), "Saving and liquidity constraints", Econometrica 59:1221-1248.

Eberly, J.C. (1994), "Adjustment of consumers" durable stocks: evidence from automobile purchases", Journal of Political Economy 102:403-436.

Eckstein, O., and A. Sinai (1986), "The mechanisms of the business cycle in the postwar era", in: R.J. Gordon, ed., The American Business Cycle: Continuity and Change (University of Chicago Press for NBER, Chicago, IL).

Engelhardt, G. (1996), "Consumption, down payments, and liquidity constraints", Journal of Money, Credit and Banking 28:255-761.

Fazzari, S.M., R.G. Hubbard and B.C. Petersen (1988), "Financing constraints and corporate investment", Brookings Papers on Economic Activity 1988(1):141-195.

Fisher, I. (1933), "The debt-deflation theory of great depressions", Econometrica 1:337-357.

Fisher, J.D.M. (1996), "Credit market imperfections and the heterogeneous response of firms to monetary shocks", Working Paper WP-96-23 (Federal Reserve Bank of Chicago, December).

Fuerst, T. (1995), "Money and financial interactions in the business cycle", Journal of Money, Credit and Banking 27:1321-1338.

Gale, D., and M. Hellwig (1985), "Incentive-compatible debt contracts: the one-period problem", Review of Economic Studies 52:647-664.

Gersbach, H. (1997), "Financial intermediation, capital spillovers, and business fluctuations", unpublished paper (Alfred-Weber-Institut, University of Heidelberg, November).

Gertler, M. (1988), "Financial structure and aggregate economic activity: an overview", Journal of Money, Credit and Banking 20(3):559-588.

Gertler, M. (1992), "Financial capacity and output fluctuations in an economy with multiperiod financial relationships", Review of Economic Studies 59:455-472.

Gertler, M. (1995), "Comment on "Money and financial interactions in the business cycle", Journal of Money, Credit and Banking 27:1342-1353.

Gertler, M., and S. Gilchrist (1993), "The role of credit market imperfections in the monetary transmission mechanism: arguments and evidence", Scandinavian Journal of Economics 95:43-64.

Gertler, M., and S. Gilchrist (1994), "Monetary policy, business cycles, and the behavior of small manufacturing firms", Quarterly Journal of Economics 59:309-340.

Gertler, M., and R.G. Hubbard (1988), "Financial factors in business fluctuations", in: Financial Market Volatility (Federal Reserve Bank of Kansas City) 33-72.

Gilchrist, S., and C.P. Himmelberg (1995), "Evidence on the role of cash flow for investment", Journal of Monetary Economics 36:541-572.

Goodfiriend, M., and R.G. King (1997), "The new neoclassical synthesis", NBER Macroeconomics Annual, 231-282.

Gourinchas, P.-O., and J. Parker (1995), "Consumption over the lifecycle", mimeograph (MIT). 
Greenwald, B., and J. Stiglitz (1993), "Financial market imperfections and business cycles", Quarterly Journal of Economics 108:77-114.

Gross, D. (1994), "The investment and financing decisions of liquidity-constrained firms", unpublished paper (MIT).

Hassett, K.A., and R.G. Hubbard (1996), “Tax policy and investment”, Working Paper No. 5683 (NBER, July).

Holmstrom, B, and J. Tirole (1997), "Financial intermediation, loanable funds, and the real sector", Quarterly Journal of Economics 113:663-692.

Hoshi, T., A.K. Kashyap and D. Scharfstein (1991), "Corporate structure, liquidity, and investment: evidence from Japanese industrial groups", Quarterly Journal of Economics 106:33-60.

Hubbard, R.G. (1995), "Is there a "credit channel" for monetary policy?", Review 77 (Federal Reserve Bank of St. Louis, May/June) 63-77.

Hubbard, R.G., A.K. Kashyap and T. Whited (1995), "Internal finance and firm investment", Journal of Money, Credit and Banking 27:683-701.

Jaffee, D.M., and J. Stiglitz (1990), "Credit rationing", in; B.M. Friedman and F.H. Hahn, Handbook of Monetary Economics (North-Holland, Amsterdam).

Jappelli, T. (1990), "Who is credit-constrained in the U.S. economy?", Quarterly Journal of Economics 105:219-234.

Jensen, M., and W. Meckling (1976), "Theory of the firm: managerial behavior, agency costs, and capital structure", Journal of Financial Economics 3:305-360.

Kaplan, S.N., and L. Zingales (1997), "Do investment-cash flow sensitivities provide useful measures of financing constraints?”, Quarterly Journal of Economics 112:159-216.

Kashyap, A.K., and J.C. Stein (1994), "Monetary policy and bank lending", in: N.G. Mankiw, ed., Monetary Policy (University of Chicago Press for NBER, Chicago, IL) 221-262.

Kashyap, A.K., O.A. Lamont and J.C. Stein (1994), "Credit conditions and the cyclical behavior of inventories", Quarterly Journal of Economics 109:565-592.

Kaufman, H. (1986), "Debt: the threat to economic and financial stability", in: Debt, Stability, and Public Policy (Federal Reserve Bank of Kansas City) 15-26.

King, R.G., and A.L. Wolman (1996), "Inflation targeting in a St. Louis model of the 21 st century", Working Paper No. 5507 (NBER, March).

Kiyotaki, N., and J. Moore (1997), "Credit cycles", Journal of Political Economy 105:211-248.

Kiyotaki, N., and J. Moore (1998), "Credit chains", unpublished paper (London School of Economics).

Krishnamurthy, A. (1997), "Collateral constraints and the credit channel", unpublished paper (MIT).

Leeper, E.M., C.A. Sims and T. Zha (1996), "What does monetary policy do?", Brookings Papers on Economic Activity 1996(2):1-63.

Levine, R. (1997), "Financial development and economic growth: views and agenda", Journal of Economic Literature 35:688-726.

Ludvigson, S. (1997), "Consumption and credit: a model of time-varying liquidity constraints", unpublished paper (Federal Reserve Bank of New York, October).

Mariger, R.P. (1987), "A life-cycle consumption model with liquidity constraints: theory and empirical results", Econometrica 55:533-558.

Mishkin, F.S. (1997), "The causes and propagation of financial instability: lessons for policymakers", in: C. Hakkio, ed., Maintaining Financial Stability in a Global Economy (Federal Reserve Bank of Kansas City).

Modigliani, F, and M. Miller (1958), "The cost of capital, corporation finance, and the theory of investment", American Economic Review 48:261-297.

Morgan, D. (1998), "The lending view of monetary policy and bank loan commitments", Journal of Money, Credit and Banking 30:102-118.

Oliner, S.D., and G.D. Rudebusch (1994), "Is there a broad credit channel for monetary policy?", unpublished paper (Board of Governors of the Federal Reserve System). 
Rotemberg, J.J., and M. Woodford (1997), "An optimization-based econometric framework for the evaluation of monetary policy", NBER Macroeconomics Annual, 297-345.

Sharpe, S. (1994), "Financial market imperfections, firm leverage, and the cyclicality of employment", American Economic Review 84:1060-1074.

Suarez, J., and O. Sussman (1997), "A stylized model of financially-driven business cycles", unpublished paper (CEMFI and Ben-Gurion University, September).

Taylor, J.B. (1993), "Discretion versus rules in practice", Carnegie-Rochester Conference Series on Public Policy 39:195-214.

Towasend, R.M. (1979), "Optimal contracts and competitive markets with costly state verification", Journal of Economic Theory 21:265-293.

Townsend, R.M. (1995), "Financial systems in northern Thai villages", Quarterly Journal of Economics 110:1011-1046.

Whited, T. (1992), "Debt, liquidity constraints, and corporatc investment: evidence from panel data", Journal of Finance 47:1425-1460.

Williamson, S. (1987), "Financial intermediation, business failures, and real business cycles", Journal of Political Economy 95:1196-1216.

Wojnilower, A. (1980), "The central role of credit crunches in recent financial history", Brookings Papers on Economic Activity 1980(2):277-326.

Zeldes, S.P. (1989), "Consumption and liquidity constraints: an empirical investigation", Journal of Political Economy 97:305-346. 